Article

\title{
Investigation of Electromagnetic, Thermal and Mechanical Characteristics of a Five-Phase Dual-Rotor Permanent-Magnet Synchronous Motor
}

\author{
Jing Zhao, Wei Liu, Bin Li *, Xiangdong Liu, Congzhe Gao and Zhongxin Gu \\ School of Automation, Beijing Institute of Technology, Beijing 100081, China; \\ E-Mails: zhaojing_bit@bit.edu.cn (J.Z.); bit_lw@yahoo.com (W.L.); xdliu@bit.edu.cn (X.L.); \\ 6120120128@bit.edu.cn (C.G.); bitzhongxingu@gmail.com (Z.G.) \\ * Author to whom correspondence should be addressed; E-Mail: libin_hit@hotmail.com; \\ Tel./Fax: +86-10-6891-2460.
}

Academic Editor: Joeri Van Mierlo

Received: 30 July 2015 / Accepted: 27 August 2015 / Published: 9 September 2015

\begin{abstract}
This paper investigates of a kind of five-phase dual-rotor permanent-magnet synchronous motor (DRPMSM), which contains dual rotors and a single stator. This kind of motor has the potential advantages of high power density, high reliability and high efficiency, which make it more appropriate for using in electric vehicles (EVs). In order to evaluate the most suitable power level for this kind of structure, the electromagnetic, the thermal and the mechanical characteristics are investigated in this paper. The length to diameter ratio of motors is researched to obtain the highest power density and then the optimum ratio is obtained. Based on the optimum ratio, the thermal characteristics are researched under natural condition and forced-air cooling condition with different wind speeds. In addition, the mechanical characteristics are analyzed under no-load and different loads conditions, respectively. All of the results are analyzed by two-dimension (2-D) and three-dimension (3-D) finite element method (FEM) simulation, which provide a good reference to select suitable power level for this kind of motor structure. Finally, a DRPMSM prototype is manufactured and tested. The experimental results effectively verify the FEM results.
\end{abstract}

Keywords: dual-rotor permanent-magnet synchronous motor (DRPMSM); electromagnetic characteristic; thermal characteristic; length to diameter ratio; mechanical characteristic; finite element method (FEM) 


\section{Introduction}

With the requirements of energy conservation and emission reduction all over the world, governments and researchers have paid more attention to electric vehicles (EVs), which has been regarded as an ideal alternative of transportation [1-4]. As the key part of EVs, the driving motor with higher power density, higher efficiency and higher stability is increasing required. Improving these properties has been a main research focus in EVs field nowadays.

In recent decades, most EVs mainly adopt the conventional motor structure with single-rotor and single-stator. However, the improvement of power density for these motors is limited due to the simple structure $[5,6]$. In order to improve the power density, a large number of researchers have paid more attention to special motors such as dual-stator permanent synchronous motor (DSPMSM) [7-10], dual-rotor permanent synchronous motor (DRPMSM) [11-14] and compound structure PMSM (CSPMSM) [15,16], which all contain double air gaps and can output more torque and power. Therefore, these motors are more suitable to be used in EVs. In order to further improve the power density, numerous methods have been proposed and adopted such as selecting suitable pole-pairs number, adding another layer of permanent magnets (PMs) at the end between the inner and outer rotor, adopting different permanent magnetic materials [17,18], adjusting the pole arcs $[19,20]$, and optimizing the ratio of length to diameter [21,22]. Besides, optimizing the ratio of rotor/stator diameter is another method to improve the machine electromagnetic characteristic [23].

In order to ensure the electromagnetic performance of motor with high power density, the thermal characteristic is also an important property which cannot be ignored. Due to the high electromagnetic load of DRPMSM with high power density, the total losses are greater than the conventional motors [24,25], which generate more heat, limit the electromagnetic load and raise the motor temperature. Therefore, heat dissipation is an important issue that should be considered in the motor design. The heat dissipation coefficient of different portions [26-33], such as air gap, outer surface of the casing and the end windings, is important to calculate temperature accurately. In [27,28], the thermal field distribution, cooling effects of the forced-air cooling and water cooling systems, heat-dissipation conditions and thermal-measuring system of CSPMSMs are analyzed by the two-dimension (2-D) and three-dimension (3-D) finite element method (FEM) simulation. In [30], the steady-state temperature field of induction motor with water cooling used for a miniature electric vehicle is investigated by the 3-D FEM simulation. Ref [31,32] mainly concentrates on the formulations used to predict the convection cooling and calculate the heat dissipation coefficient within the machine. In [33], the authors investigate the thermal distribution and calculated the convection heat transfer coefficients of dual-rotor permanent magnet induction machine.

In addition, mechanical characteristic including vibration and noise is also an important factor, which influences the service life and the operating reliability of the motor. The electromagnetic force caused by the interaction of the stator core and PMs will lead to mechanical deformation and vibration of stator. Thus, many researchers have investigated this problem. In [34,35], the electromagnetic force is calculated by the radial and tangential components of the air gap flux densities, and then the electromagnetic vibration and noise in the PMSM is evaluated. The distribution characteristics of radial electromagnetic force were theoretically analyzed by FEM method [34]. The results in [36-38] show that the lowest mode number of radial force harmonics is the greatest common divisor of pole 
and slot combination. The effect of rotor step skewed on noise and vibration of the IPMSM were introduced in [39]. In [40], the electromagnetic forces acted on the damping windings and engendered in the rated and the three-phase short-circuit conditions were analyzed. In [41], the influence of slip, the distributed stator winding, and pulse width modulation inverter on the electromagnetic force are clarified. The hybrid rotor of magnetic-bearing switched-reluctance motor (MBSRM) are designed to analyze the electromagnetic force loads and observe the influence on electromagnetic force [42].

Considering the requirements of high power density, high efficiency and high-tolerant capability of EVs, a five-phase DRPMSM is investigated in this paper. This kind of motor has the potential of good fault tolerant capability and high torque density, which makes it appropriate for use in EVs. The structure and winding distribution of the five-phase DRPMSM is shown in Figures 1 and 2. Briefly, the five-phase DRPMSM contains inner and outer rotors with PMs, inner and outer air gaps, and a mutual stator that has outside five-phase winding and inside five-phase winding. The inner and outer rotors are connected by the end flange. The stator is nest between the inner and outer rotors. The inner rotor and inside stator winding operates as one motor called inner-motor, and the outer rotor and outside stator winding operates as another one called outer-motor. The inner and outer motors adopt the same pole-slot matching. The PMs on the double rotors are placed facing each other directly and adopted the consistent magnetized direction. As for this magnetization, the flux does not link through the stator yoke, and the stator yoke of N-S type model can be designed thinner further. However, the thickness of the stator yoke should ensure the mechanical strength of the motor.

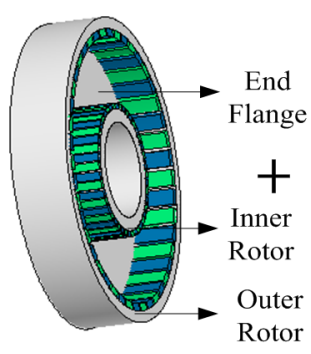

Rotor

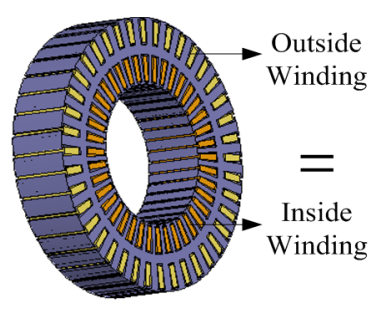

Stator

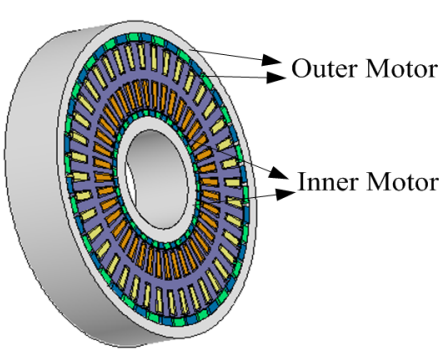

Five-phase DRPMSM

Figure 1. The structure of the five-phase dual-rotor permanent-magnet synchronous motor (DRPMSM).

For different power level motors, the contribution of the inner motor to the performance of the DRPMSM is different due to the special structure. For small power level motor, the internal space of inner motor is very limited, which causes small output torque and power contribution. For a high power level motor, the radius between inner-motor air gap and outer-motor air gap has a small difference, which makes the inner motor have a great contribution to the whole machine. This will cause different power density for different power level motors. Besides, two layers of windings including inside winding and outside winding in stator will produce more heat source and have higher temperature than single layer winding. Therefore, the thermal characteristic is one key part to be researched. However, different power levels DRPMSMs have different heat dissipating coefficients. These factors result in different thermal characteristics for DRPMSMs with different power level. In addition, the mechanical characteristics of DRPMSMs with different power level are also different. Therefore, it is important and necessary to evaluate the mechanical strength for each power level motor 
to guarantee the reliability. However, the comprehensive evaluation of the electromagnetic, thermal and mechanical characteristics of a five-phase DRPMSM has been reported little.

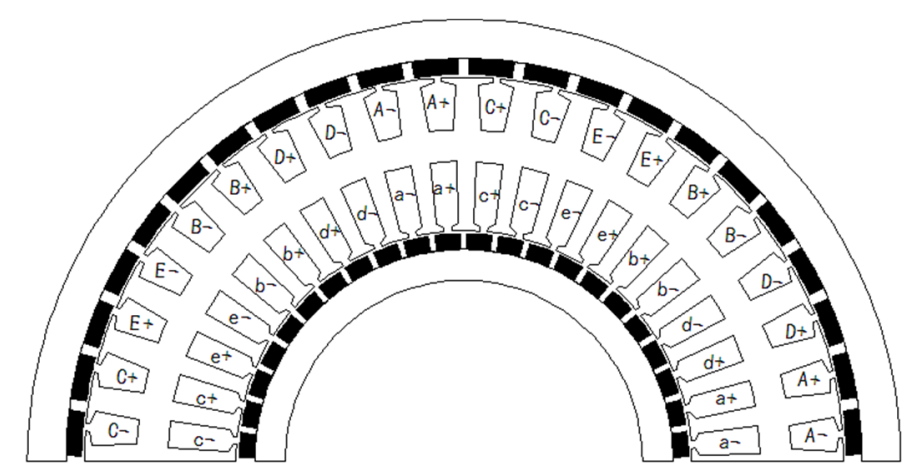

Figure 2. Coil connection of the half-model DRPMSM.

Considering the different performance of the five-phase DRPMSMs with different power level, the electromagnetic, thermal and mechanical characteristics of five-phase DRPMSMs with different power level are investigated and compared in this paper. Firstly, the electromagnetic characteristics such as efficiency, active mass, power density, power versus mass and so on, are analyzed and compared to obtain the optimum model among five motors with different power levels by the 2-D FEM. Secondly, the thermal distribution and effect of forced-air cooling conditions are investigated by the 3-D FEM. Thirdly, the normal electromagnetic forces, the mechanical deformation and stress density distribution of stator are calculated under different load conditions. Finally, a prototype of the five-phase DRPMSMs is manufactured, and the experiments are carried out to validate the simulation results.

\section{Electromagnetic Characteristic Analysis of the Dual-Rotor Permanent-Magnet Synchronous Motor (DRPMSM)}

Considering that the ratio $k$ of length to diameter is one of the most important parameters to affect the power density, the influence law of the ratio $k$ on motor electromagnetic performances is analyzed in this section.

First of all, the total effective volume of the motor is defined as:

$$
V=\pi D_{\mathrm{o}}^{2} L / 4
$$

where $V$ is effective volume of DRPMSM; $D_{\mathrm{o}}$ is the outer diameter of DRPMSM; $L$ is the active length of stator.

The ratio $k$ is expressed as:

$$
k=L / D_{\mathrm{o}}
$$

When the power level of the motor is fixed, the volume $V$ will be determined. Therefore, the total volume is constant in the process of changing the ratio $k$ for the same power level motor. In other words, with the diameter $D_{\mathrm{o}}$ increasing, the length $L$ will decrease. Five different power level motors of $1 \mathrm{~kW}$, $5 \mathrm{~kW}, 10 \mathrm{~kW}, 20 \mathrm{~kW}$ and $70 \mathrm{~kW}$ are selected to be investigated by the 2-D FEM. In order to insure the comparison more reasonably, partial parameters of motor with different power levels should remain the same as shown in Table 1. 
Table 1. Partial Parameters of the DRPMSM.

\begin{tabular}{ccc}
\hline Quantity & Value & Unit \\
\hline Levels of maximum power & $1 / 5 / 10 / 20 / 70$ & $\mathrm{~kW}$ \\
Current density & 4.48 & $\mathrm{~A} / \mathrm{mm}^{2}$ \\
Line electrical load & $10.95 / 11.25 / 14.5 / 21.2 / 24$ & $\mathrm{kA} / \mathrm{m}$ \\
Inner/outer air gap length & $0.75 / 0.75$ & $\mathrm{~mm}$ \\
Stator stack factor & 0.96 & - \\
Rated speed & 600 & $\mathrm{rpm}$ \\
Phase & 5 & - \\
Magnet relative permeability & 1.06 & $\mathrm{~T}$ \\
\hline
\end{tabular}

\subsection{Losses of the Dual-Rotor Permanent-Magnet Synchronous Motor (DRPMSM)}

As the losses affect the motor efficiency and temperature rise, they cannot be ignored in the motor. The losses mainly in motor contain iron loss in stator and rotor iron, eddy current loss in PMs, copper loss in windings and mechanical loss. Considering the mechanical loss are small, it can be neglected in this paper.

The value of iron loss is computed by:

$$
P_{\mathrm{Fe}}=\left(K_{\mathrm{e}} f^{2} B_{\text {max }}^{2}+K_{\mathrm{h}} f B_{\text {max }}^{x}\right) m_{\mathrm{Fe}}
$$

where $P_{\mathrm{Fe}}$ is the iron loss; $K_{\mathrm{e}}$ is the coefficient of eddy loss, $K_{\mathrm{h}}$ is the coefficient of hysteresis loss, $K_{\mathrm{e}}$ and $K_{\mathrm{h}}$ are determined by the inherent properties of materials; $B_{\max }$ is the amplitude of magnetic density; $f$ is the frequency of magnetic field; $x$ is a constant, which is determined by $B_{\max }$ [31], and the relationship between $x$ and $B_{\max }$ is shown in Table $2 ; m_{\mathrm{Fe}}$ is the active weight of iron.

Table 2. The value of parameter $x$.

\begin{tabular}{cccc}
\hline$B(\mathbf{T})$ & $\mathbf{0 - 1 . 4}$ & $\mathbf{1 . 4 - 1 . 6}$ & $\mathbf{2 1 . 6}$ \\
\hline$x$ & 1.7 & 2 & 1.2 \\
\hline
\end{tabular}

The eddy current loss in PMs is calculated by [32]:

$$
P_{\mathrm{PM}}=\sum_{n}\left\{\int_{\mathrm{PM}} \frac{\left|J_{\mathrm{n}}\right|^{2}}{2 \sigma} \mathrm{d} v\right\}
$$

where $P_{\mathrm{PM}}$ is the eddy loss; $J_{n}$ is the current density of PM; $\sigma$ is the conductivity of PM.

The copper loss is related to the root mean square (RMS) of phase current and phase resistance, which is expressed as:

$$
P_{\mathrm{cu}}=m I_{r m s}^{2} R
$$

where $P_{\mathrm{cu}}$ is the copper loss; $m$ is the number of phases; $I_{r m s}$ is the phase current $R M S ; R$ is the phase resistance.

Therefore, the total losses are calculated by:

$$
P_{\text {total }}=P_{\mathrm{Fe}}+P_{\mathrm{cu}}+P_{\mathrm{PM}}
$$




\subsection{Electromagnetic Characteristic of the Dual-Rotor Permanent-Magnet Synchronous Motor} (DRPMSM)

In this section, five aspects of the electromagnetic characteristics including power per unit active volume (power density), the total losses, mechanical efficiency, active mass of material and power per unit active mass, are researched and compared with the ratio $k$ varying.

Firstly, the output average torque can be obtained by FEM, and the electromagnetic power is calculated by:

$$
P_{\mathrm{e}}=T_{\mathrm{e}} \Omega
$$

where $P_{\mathrm{e}}$ is the electromagnetic power; $T_{\mathrm{e}}$ is the output average torque; $\Omega$ is the angular velocity, whose value is relative with the rated speed $n$ shown as:

$$
\Omega=2 \pi \frac{n}{60}
$$

The power per unit active volume is expressed as:

$$
\rho=P_{\mathrm{e}} / V
$$

Secondly, the efficiency $\eta$ is expressed as:

$$
\eta=P_{\mathrm{e}} /\left(P_{\mathrm{e}}+P_{\text {total }}\right)
$$

Thirdly, the material masses of the motor mainly contain stator core, magnet, rotor core, copper, shaft and other mass. In this paper, the first four masses are considered as the active mass:

$$
m_{\text {total }}=m_{\text {stator }}+m_{\mathrm{PM}}+m_{\text {copper }}+m_{\text {rotor }}
$$

where $m_{\text {stator, }} m_{\text {rotor, }} m_{\mathrm{PM}}$, and $m_{\text {copper }}$ are the stator core steel mass, rotor core steel mass, permanent magnet mass and winding copper mass, respectively; $m_{\text {total }}$ is the active mass of motor.

Fifthly, the power per unit active mass is obtained by:

$$
p_{\mathrm{m}}=P_{\mathrm{e}} / m_{\mathrm{total}}
$$

\subsection{Simulation Results and Analysis}

The influences of the ratio $k$ on the performances of the DRPMSM are shown in Figures 3-5. Figure 3a,b shows the effect of the ratio $k$ on power per unit volume (power density) and the output average torque; Figure $4 \mathrm{a}, \mathrm{b}$ shows the effect of the ratio $k$ on active mass and power per unit active mass; Figure 5a,b shows the effect of the ratio $k$ on total losses and efficiency. 


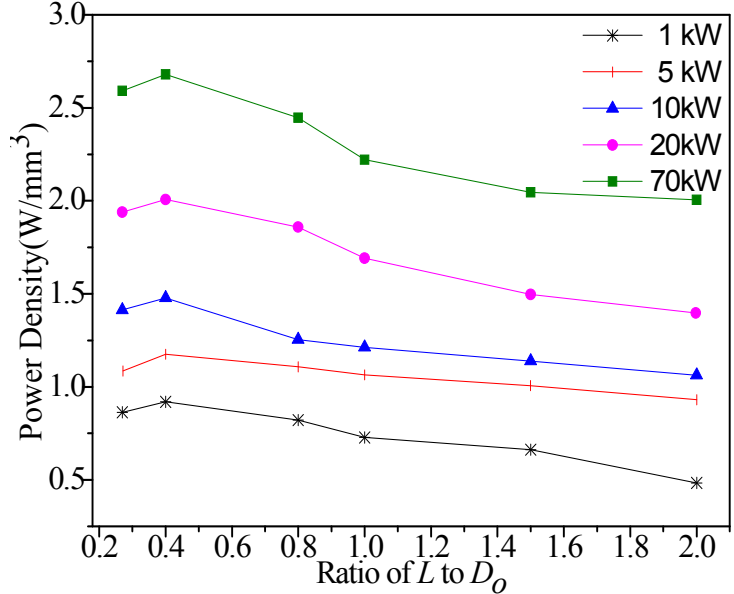

(a)

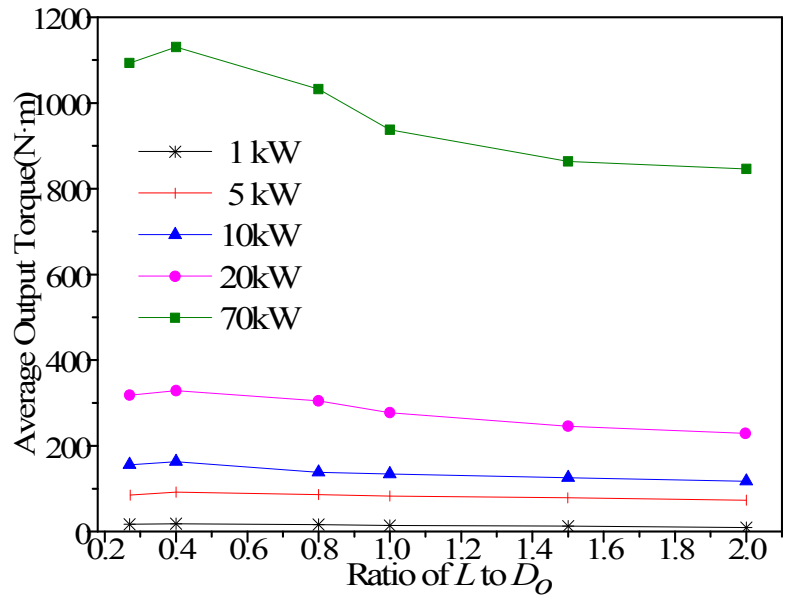

(b)

Figure 3. Influences of the ratio $k$ on (a) power per unit active volume; and (b) average output torque.

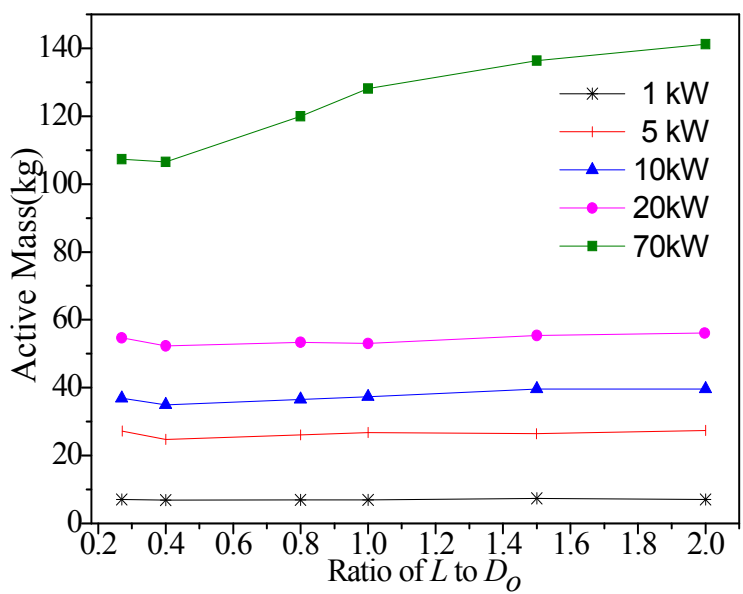

(a)

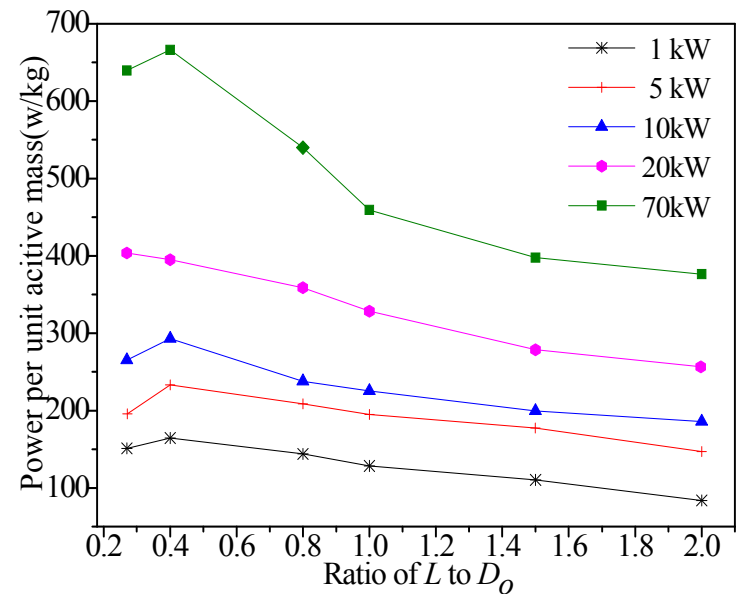

(b)

Figure 4. Influences of the ratio $k$ on (a) active mass of material; and (b) power per unit active mass.

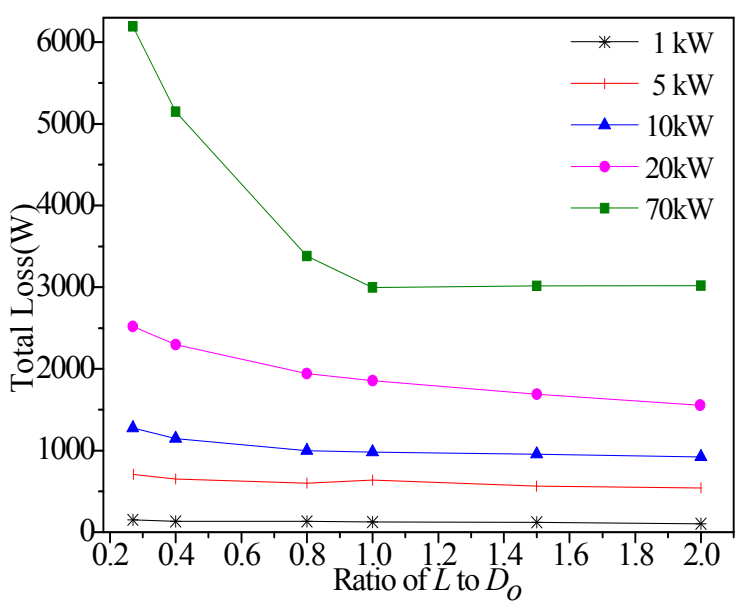

(a)

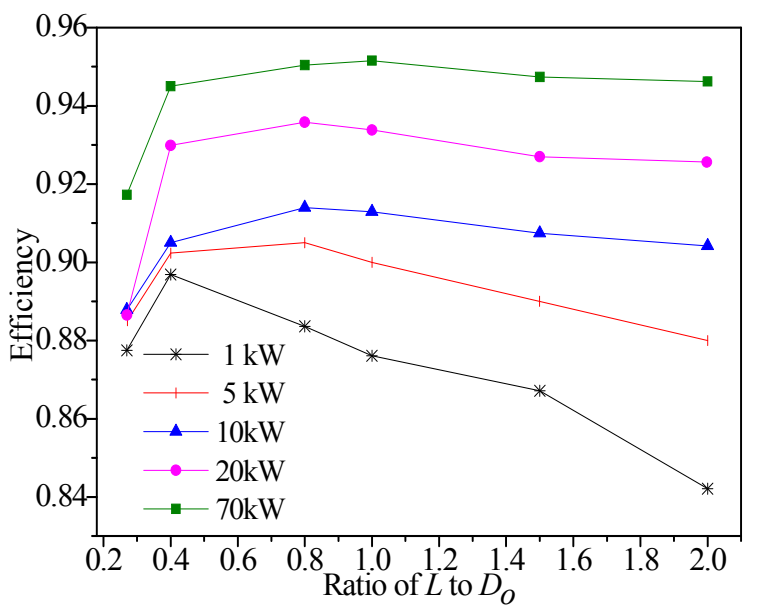

(b)

Figure 5. Influences of the ratio $k$ on (a) total loss; and (b) efficiency. 
Comparing Figures $3 a, b$ and $4 b$, all of them have the similar variation trend. It can be seen that the highest power density, highest average output torque and the highest power per unit active mass are achieved around the ratio of 0.4 and that will decrease as the ratio $k$ increases beyond 0.4 . The lowest active mass is also achieved around 0.4 of the ratio and the variation tendency presents "V" with increasing the ratio as shown in Figure 4a. In Figure 5a, the total losses decrease with the increasing ratio $k$ and they decreases quickly at first and then slowly. Figure $5 \mathrm{~b}$ indicates that the highest efficiency is obtained around 0.8 of the ratio and that decreases as the ratio increases beyond 0.8 .

According to Figures 3 and 5, it can be found that as the motor power levels increases from $1 \mathrm{~kW}$ to $70 \mathrm{~kW}$, the power density, average output torque, active mass of material, power per active mass and efficiency increase more quickly. This indicates that the high power level can be designed to obtain the high power density for DRPMSM.

Generally, from Figures 3-5, the highest power density, the highest output average torque, the lowest active mass and the highest power per unit active mass are achieved around the ratio of 0.4. The efficient does not reach the highest point as the ratio is 0.4 , but the efficiency has little change as the ratio increases beyond 0.4 . Therefore, the ratio $k$ of 0.4 is selected for five different power level motors to investigate the thermal and mechanical characteristics of DRPMSM.

Based on the optimal models of five different power levels motors, the flux lines and flux densities distribution at the rated condition are shown in Figures 6 and 7.

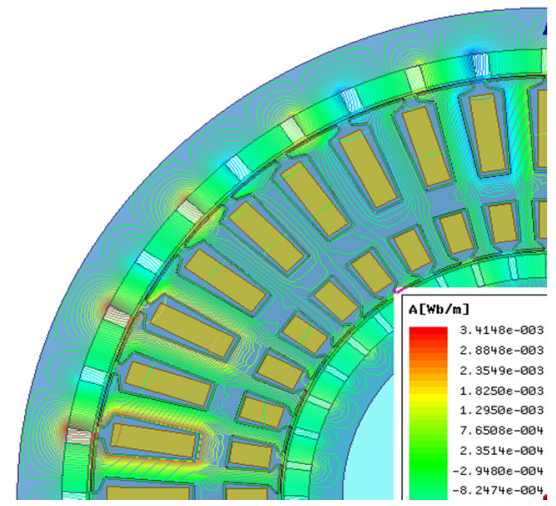

(a)

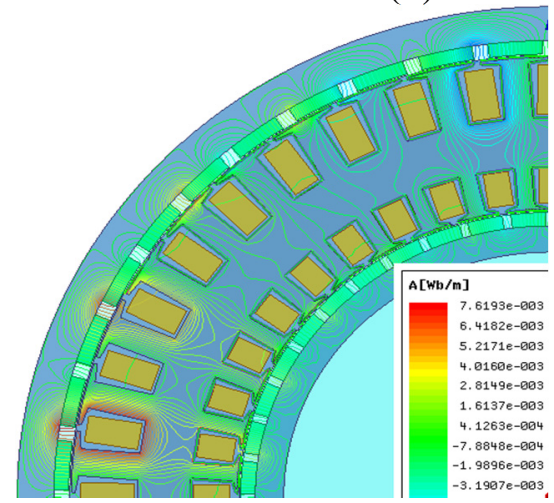

(c)

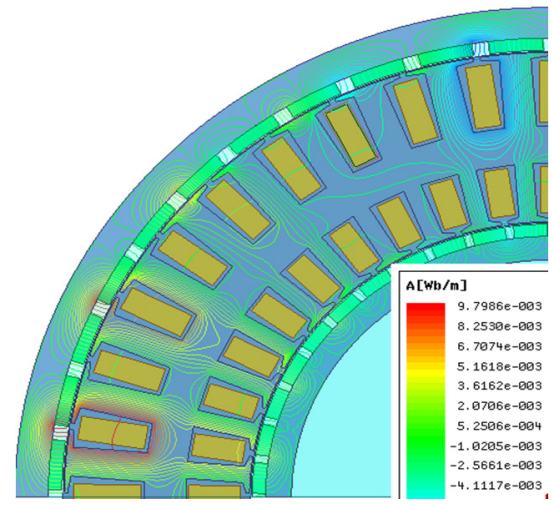

(d)

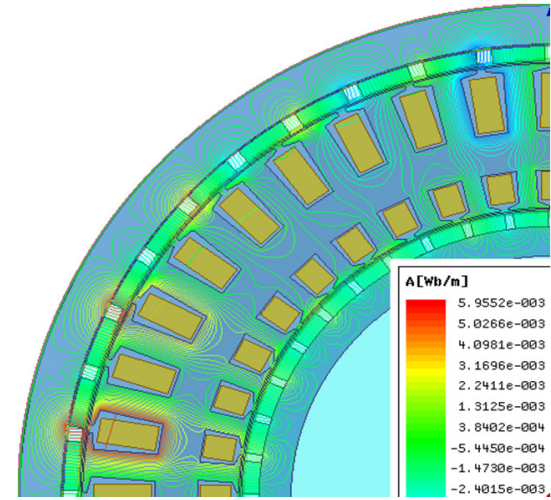

(b)

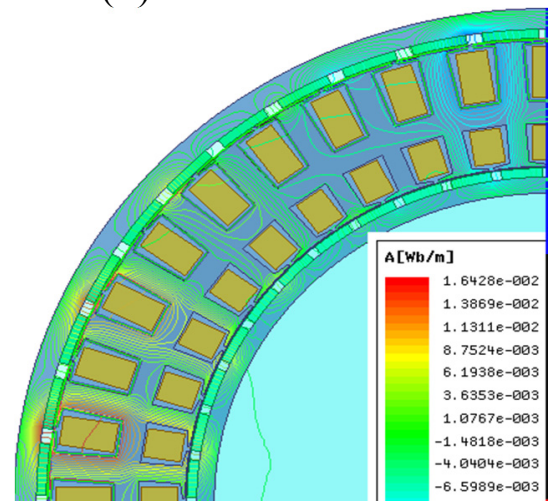

(e)

Figure 6. The flux lines distribution of (a) $1 \mathrm{~kW}$; (b) $5 \mathrm{~kW}$; (c) $10 \mathrm{~kW}$; (d) $20 \mathrm{~kW}$; and (e) $70 \mathrm{~kW}$. 


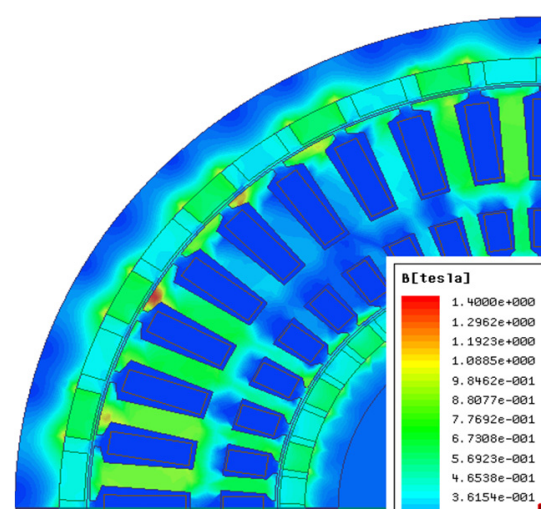

(a)

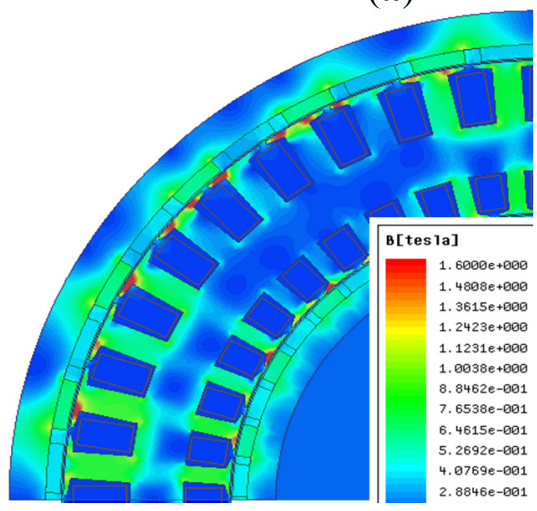

(c)

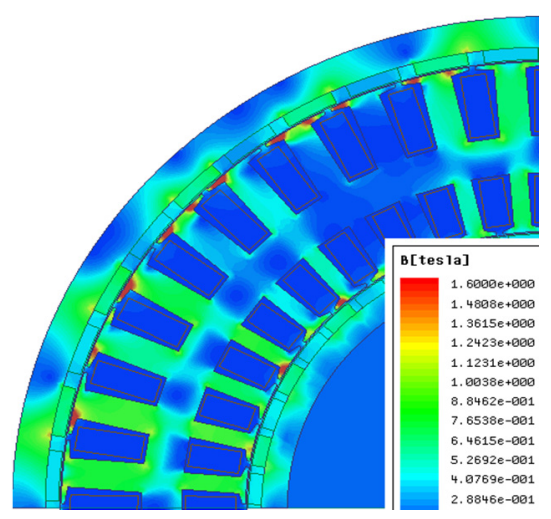

(d)

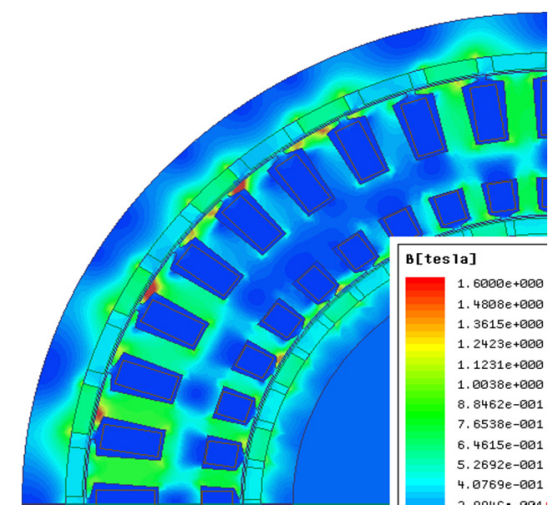

(b)

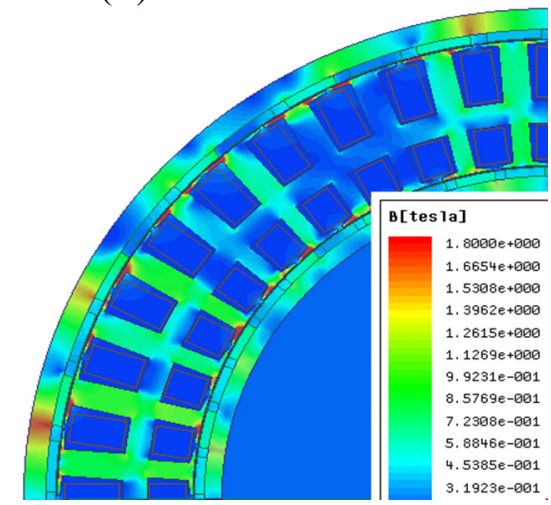

(e)

Figure 7. The flux densities distribution of (a) $1 \mathrm{~kW}$; (b) $5 \mathrm{~kW}$; (c) $10 \mathrm{~kW}$; (d) $20 \mathrm{~kW}$; and (e) $70 \mathrm{~kW}$.

The output torque performances of five different power levels motors in different load condition are shown in Figure 8 and the comparisons are listed in Table 3. As can be seen from Figure 8 and Table 3, the output average torque increases with the power level increasing. For the same power level, the output torque increases and torque ripple decreases when the current increases. In the following contents, the thermal characteristic will be investigated under the rated condition for five different power levels motors; the mechanical characteristic will be investigated under different load conditions.

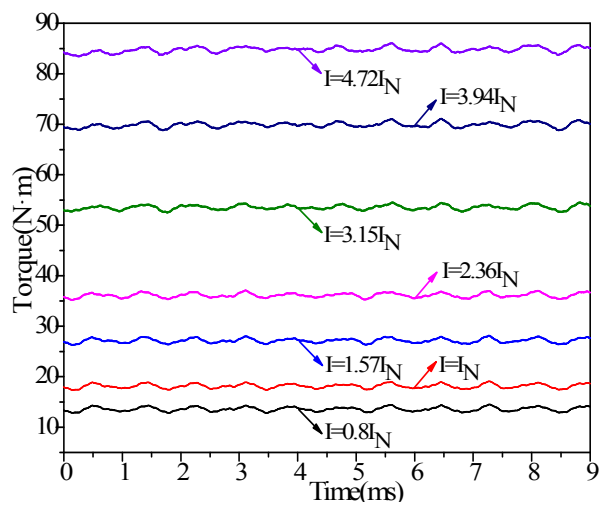

(a)

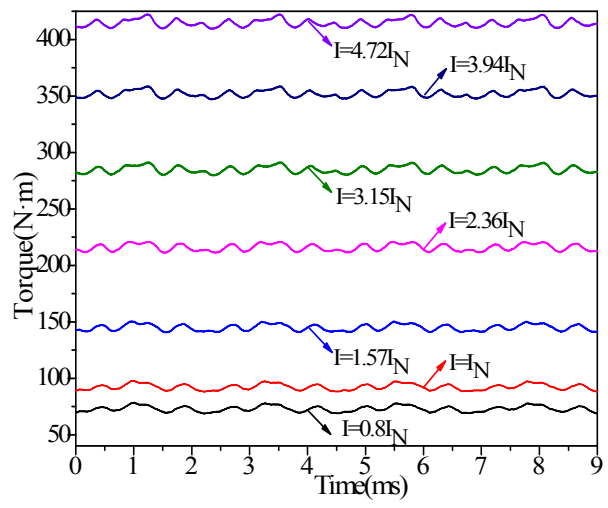

(b)

Figure 8. Cont. 


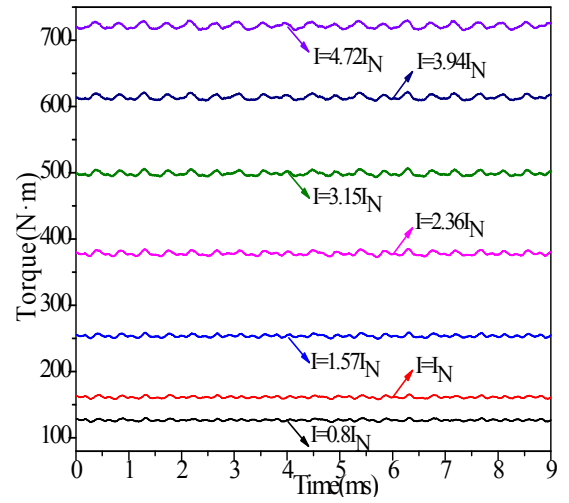

(c)

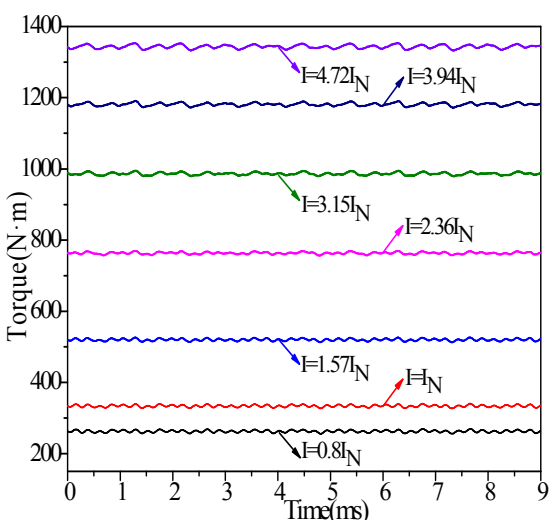

(d)

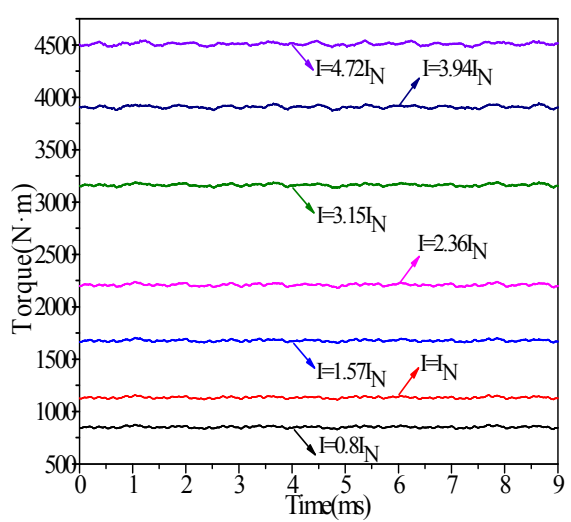

(e)

Figure 8. The torque performances of (a) $1 \mathrm{~kW}$; (b) $5 \mathrm{~kW}$; (c) $10 \mathrm{~kW}$; (d) $20 \mathrm{~kW}$; (e) $70 \mathrm{~kW}$.

Table 3. The torque performances of DRPMSM in different load condition.

\begin{tabular}{ccccccc}
\hline Power level & & $\mathbf{1 ~ k W}$ & $\mathbf{5 ~ k W}$ & $\mathbf{1 0} \mathbf{~ k W}$ & $\mathbf{2 0} \mathbf{~ k W}$ & $\mathbf{7 0 ~} \mathbf{~ W}$ \\
\hline & $0.8 \mathrm{I}_{\mathrm{N}}$ & 13.58 & 72.86 & 126.71 & 262.52 & 850.63 \\
& $\mathrm{I}_{\mathrm{N}}$ & 18.15 & 92.23 & 161.36 & 333.56 & 1132.9 \\
Output average torque & $1.57 \mathrm{I}_{\mathrm{N}}$ & 27.14 & 144.79 & 253.76 & 519.79 & 1675.7 \\
$(\mathrm{~N} \cdot \mathrm{m})$ & $2.36 \mathrm{I}_{\mathrm{N}}$ & 36.16 & 215.98 & 378.45 & 763.85 & 2210.2 \\
& $3.15 \mathrm{I}_{\mathrm{N}}$ & 53.55 & 284.85 & 498.97 & 986.65 & 3162.2 \\
& $3.94 \mathrm{I}_{\mathrm{N}}$ & 69.88 & 352.02 & 613.89 & 1181.3 & 3906.6 \\
& $4.72 \mathrm{I}_{\mathrm{N}}$ & 84.76 & 414.71 & 721.58 & 1343.4 & 4507.8 \\
\hline \multirow{3}{*}{ Torque ripple (\%) } & $0.8 \mathrm{I}_{\mathrm{N}}$ & 12.4 & 13.29 & 5.18 & 5.34 & 5.41 \\
& $\mathrm{I}_{\mathrm{N}}$ & 9.42 & 1048 & 4.62 & 4.09 & 4.1 \\
& $1.57 \mathrm{I}_{\mathrm{N}}$ & 6.65 & 6.67 & 3.72 & 2.57 & 2.92 \\
& $2.36 \mathrm{I}_{\mathrm{N}}$ & 5.21 & 4.48 & 3.22 & 1.77 & 2.61 \\
& $3.15 \mathrm{I}_{\mathrm{N}}$ & 3.55 & 3.92 & 2.64 & 1.54 & 1.67 \\
& $3.94 \mathrm{I}_{\mathrm{N}}$ & 3.23 & 3.25 & 2.17 & 1.47 & 1.83 \\
& $4.72 \mathrm{I}_{\mathrm{N}}$ & 3.06 & 3.02 & 2.11 & 1.45 & 1.5 \\
\hline
\end{tabular}

\section{Thermal Characteristic Analysis of the Dual-Rotor Permanent-Magnet Synchronous Motor (DRPMSM)}

Due to the DRPMSM having double winding layers, more heat will be produced than the traditional single-stator/single-rotor motor. In addition, the heat produced by the stator is difficult to be dissipated as the stator is placed between the inner and outer rotor. Hence, it is very important to evaluate the thermal characteristic of DRPMSM to avoid the excessive temperature damaging the motor. In order to make DRPMSM run safely, a large number of methods can be used to improve the machines' heat dissipation capability of the motor, such as water cooling, forced-air cooling, oil cooling, and so on. In this paper, the impact of natural condition and forced-air cooling condition with different wind speeds on the temperature of the five motors with different power level is analyzed. In order to make the calculation more conveniently and reasonably, the following assumptions are made for the motor model: 
a) The heat sources are uniformly distributed on the corresponding regions in the motors.

b) The temperature gradient of motor is zero along the axial direction.

c) The main transfer ways in DRPMSM are heat conduction and convection, so the effect of heat radiation is very small. In this paper, the heat radiation is neglected.

d) The heat conduction of each material is isotropic.

e) The thermal conduction of the shaft is insulated.

\subsection{Boundary Conditions}

Because of the complications of simultaneous, the uncertainty direction of flow and the mechanical movement, the fluid filed and thermal field are combined together. This raises the difficulty of the thermal filed calculation precisely. Therefore, the exact boundary conditions should be set up firstly. Due to the symmetrical feature of the DRPMSM structure, a half of model is built and simulated by the 3-D FEM, as shown in Figure 9.

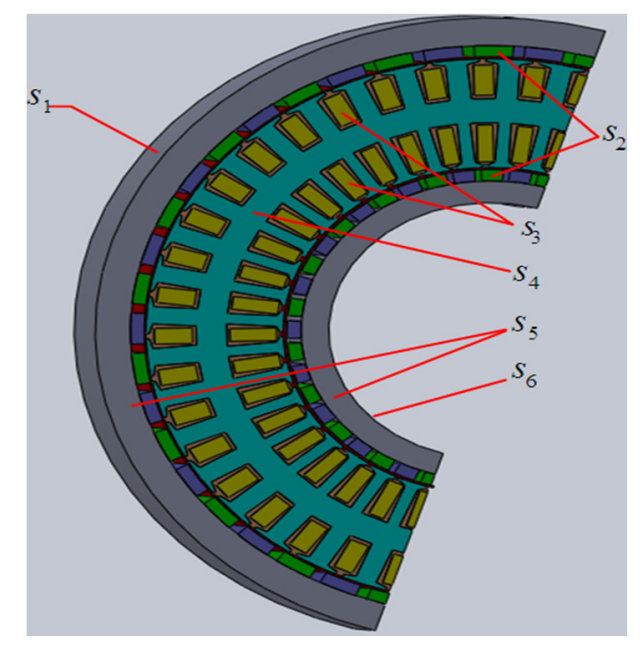

Figure 9. Different boundary surfaces of 3-D DRPMSM model.

According to the theory of heat conduction, the heat conduction equation of 3-D steady-state temperature field is described by:

$$
\frac{\partial}{\partial x}\left(\lambda_{x} \frac{\partial T}{\partial x}\right)+\frac{\partial}{\partial y}\left(\lambda_{y} \frac{\partial T}{\partial y}\right)+\frac{\partial}{\partial z}\left(\lambda_{z} \frac{\partial T}{\partial z}\right)=-q(x, y, z)
$$

where $T$ is temperature (in degree Celsius); $k$ is thermal conductivity coefficient; $q$ is the heat generation rate per unit volume; $\lambda_{x}, \lambda_{y}, \lambda_{z}$ is heat transfer coefficient of the direction of $x, y, z$. According to the Equation (13), it can be divided into three different boundaries in this paper.

The first boundary:

$$
T=T_{\mathrm{S}}
$$

The second boundary:

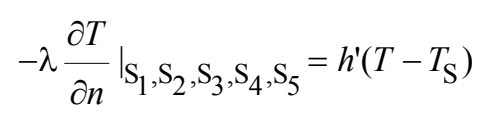


The third boundary:

$$
\left.\lambda \frac{\partial T}{\partial n}\right|_{S_{6}}=0
$$

where $T_{\mathrm{s}}$ is surrounding temperature (in degree Celsius), $S_{1}, S_{2}, S_{3}, S_{4}, S_{5}, S_{6}$ are the outer surface of outer rotor, the end edge of PMs, the end edge of coil windings, the end edge of stator, the end edge of outer and inner rotor, and the inner surface of inner rotor, respectively; $h^{\prime}$ is the heat transfer coefficient.

\subsection{Determination of Internal Heat Source in Dual-Rotor Permanent-Magnet Synchronous Motor (DRPMSM)}

In order to evaluate 3-D steady-state temperature distribution, the heat source including the eddy loss in PMs, copper loss in stator windings, iron loss in stator and rotor under rated load condition are calculated by the Equations (3)-(5). The losses of different parts are as shown in Table 4.

Table 4. Losses of different parts under rated load condition.

\begin{tabular}{ccccc}
\hline Power level $(\mathbf{k W})$ & Iron loss of stator $(\mathbf{W})$ & Iron loss of rotor $(\mathbf{W})$ & PMs loss $(\mathbf{W})$ & Copper loss $(\mathbf{W})$ \\
\hline 1 & 48 & 33.16 & 12.82 & 35.44 \\
5 & 235.1 & 140.8 & 149.5 & 99.17 \\
10 & 389.8 & 166 & 366.96 & 153.28 \\
20 & 608.7 & 258.5 & 401.5 & 287.57 \\
70 & 1212.1 & 579.6 & 2797.6 & 694.4 \\
\hline
\end{tabular}

According to Table 4, the losses of each part will increase with the increasing of the power level of the motors. However, the losses of different parts cannot be directly applied to the corresponding parts in the Ansys software (Ansys company, Canonsburg, PA, USA). The volume of each part is obtained by the geometry modular in Ansys software. Therefore, the loss versus active volume of each part can be expressed as:

$$
\rho^{\prime}=p^{\prime} / V^{\prime}
$$

where $p^{\prime}$ is the losses of stator, rotor, PMs and copper; $V^{\prime}$ is the active volume of stator, rotor, PMs and copper; $\rho^{\prime}$ is the loss per active volume.

The calculated values of losses versus active volume for each part are shown in Table 5.

Table 5. Loss versus active volume of each part.

\begin{tabular}{ccccc}
\hline Power level $(\mathbf{k W})$ & $\boldsymbol{\rho}_{\text {'stator }}^{\prime}\left(\mathbf{w} / \mathbf{m m}^{\mathbf{3}}\right)$ & $\boldsymbol{\rho}_{\text {rotor }}^{\prime}\left(\mathbf{w} / \mathbf{m m}^{\mathbf{3}}\right)$ & $\boldsymbol{\rho}_{\text {PMs }}^{\prime}\left(\mathbf{w} / \mathbf{m m}^{\mathbf{3}}\right)$ & $\boldsymbol{\rho}_{\text {copper }}^{\prime}\left(\mathbf{w} / \mathbf{m m}^{\mathbf{3}}\right)$ \\
\hline 1 & 0.000159 & 0.0000705 & 0.000136 & 0.000211 \\
5 & 0.0001859 & 0.0000935 & 0.000437 & 0.000191 \\
10 & 0.000197 & 0.0000858 & 0.000833 & 0.000193 \\
20 & 0.000481 & 0.000104 & 0.000653 & 0.000208 \\
70 & 0.00022 & 0.000137 & 0.000205 & 0.00228 \\
\hline
\end{tabular}

$\rho^{\prime}$ stator, $\rho^{\prime}$ rotor, $\rho^{\prime}$ PMs and $\rho^{\prime}$ copper are the stator loss per active volume of stator, rotor loss per active volume of rotor, PMs loss per active volume of PMs, copper loss per active volume of copper, respectively. 


\subsection{Thermal Parameter Calculation}

As for the slot thermal model, the distribution of conductors in the slot is random, there is the air gap among copper conductors which causes the uneven distribution of heat in the slot. Meanwhile, other materials including the air gap layer among the copper conductors and insulation varnish layer cannot be divided exactly. These aspects bring more difficult to calculate the slot thermal conductivity accurately.

Because of the random distribution of the conductors, the air gap among copper conductors, and the insulation varnish layer contained in the slot, the heat distribution in the slot is uneven. Therefore, the solution to get an equivalent thermal conductivity is adopted; all round conductors in one slot are considered as a conductor block [32], as shown in Figure 10. In other words, the area of the conductor block is the sum of the areas of all the conductors, and the conductor block is put in the center of the slot. The equivalent insulation between the copper windings and the iron core consists of the slot insulation, the air gap between the slot insulation and the laminations, the insulation varnish of the windings, and the air gaps between the conductors. After equivalent calculation, the thickness of the slot insulations between the copper conductor and stator iron for 1, 5, 10, 20 and $70 \mathrm{~kW}$ motors are equivalent to $0.5,0.7,1,1.5$ and $2.3 \mathrm{~mm}$ in the inside and outside slots.

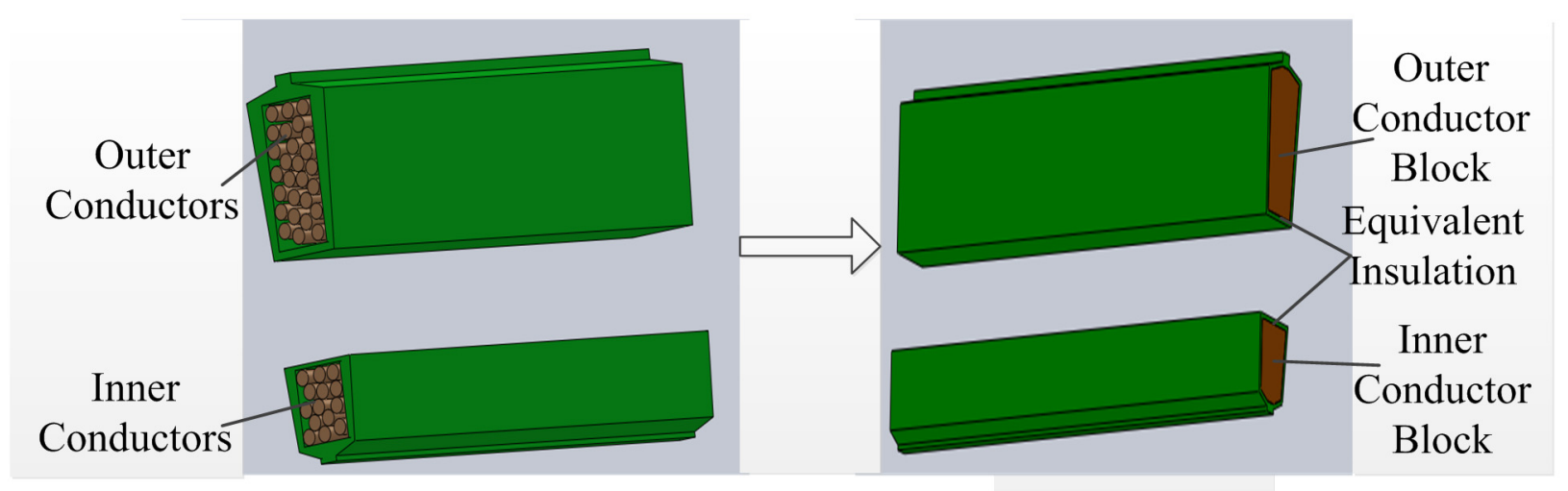

Figure 10. Thermal equivalent model of the inner and outer windings.

When the DRPMSM is operating, the air between the stator and outer rotor as well as that between the stator and the inner rotor flows relatively. This brings about convective heat transfer between the air gap and neighbor parts including the outer surface of the inner rotor PM, the inner surface of the outer rotor PM, the inner and outer surface of the stator, and so on. An effective heat transfer coefficient of air gap is adopted to analyze and expressed as [27]:

$$
\begin{gathered}
\lambda_{\delta}=0.0019 \cdot \eta^{-2.9084} \cdot \operatorname{Re}^{0.4614 \cdot \operatorname{In}(3.33361 \cdot \eta)} \\
\operatorname{Re}=R_{\mathrm{o}} \frac{\omega \delta}{\mathrm{v}} \\
\eta=\frac{R_{\mathrm{o}}}{R_{\mathrm{i}}}
\end{gathered}
$$

where $\lambda_{\delta}$ is the effective heat transfer coefficient of the air gap; $R_{\mathrm{o}}$ is the outer radius of air gap; $R_{\mathrm{i}}$ is the inner radius of air gap; $\delta$ is the length of air gap; $v$ is the coefficient of air kinematic viscosity. 
According to Equations (18)-(20), the thermal coefficient of the air gap is related to the inner and outer radius of the air gap. Therefore, the thermal coefficient is different for the dual-rotor motors with different power level. Besides, for the motor with the same power level, the thermal coefficient of the inner and outer air gap is also different. Therefore, the calculated thermal coefficients are listed in Table 6.

Table 6. Thermal coefficient of air gap.

\begin{tabular}{lccccc}
\hline Power level & $\mathbf{1 ~ k W}$ & $\mathbf{5} \mathbf{k W}$ & $\mathbf{1 0} \mathbf{k W}$ & $\mathbf{2 0} \mathbf{k W}$ & $\mathbf{7 0 ~ k W}$ \\
Position & & & & & \\
\hline Inner air gap $(\mathrm{W} / \mathrm{m} \cdot \mathrm{K})$ & 0.0284 & 0.039 & 0.0423 & 0.0437 & 0.0579 \\
Outer air gap $(\mathrm{W} / \mathrm{m} \cdot \mathrm{K})$ & 0.0389 & 0.0493 & 0.0542 & 0.0576 & 0.0694 \\
\hline
\end{tabular}

The end heat dissipation of the motor is also one of the most important ways for the motor cooling. The equivalent heat-exchange coefficient $h$ of the outer surface of the end parts including wingdings, stator and rotor are calculated by:

$$
h=41.4+6.22 v_{1}
$$

where $v_{1}$ is the wind speed of the object ends.

For the rotor, the $v_{1}$ is calculated by:

$$
v_{1}=\pi n\left(D_{\mathrm{o}}+D_{\mathrm{i}}\right) / 120
$$

For the stator, the $v_{1}$ is calculated by:

$$
v_{1}=\pi n\left(D_{\mathrm{os}}+D_{\mathrm{is}}+\delta\right) / 120
$$

where $D_{\mathrm{o}}$ is the outer diameter of inner or outer rotor, $D_{\mathrm{i}}$ is the inner diameter of inner or outer rotor, $\mathrm{n}$ is the speed of rotor; $D_{\mathrm{os}}$ is the stator outer diameter, $D_{\text {is }}$ is the stator inner diameter, $\delta$ is the length of air gap.

As is known, cooling air flow through the surrounding environment makes a great contribution to the heat dissipation of the motor. The heat-exchange coefficient of the outer rotor surface can be obtained by:

$$
a=9.73+14 v_{2}^{0.62}
$$

where $v_{2}$ is the airflow velocity on the outer rotor surface, which can be measured by the wind speed

\begin{tabular}{|c|c|c|c|}
\hline Position & $\begin{array}{l}\text { Density } \\
\left(\mathrm{kg} / \mathrm{m}^{3}\right)\end{array}$ & $\begin{array}{c}\text { Thermal coefficient } \\
(\mathrm{W} / \mathbf{m} \cdot \mathbf{K})\end{array}$ & $\begin{array}{c}\text { Specific heat capacity } \\
(\mathrm{J} / \mathrm{kg} \cdot \mathrm{K})\end{array}$ \\
\hline Stator winding copper & 8900 & 387 & 407 \\
\hline $\begin{array}{l}\text { Stator winding equivalent insulation } \\
\text { (H level insulating paper) }\end{array}$ & 2300 & 0.16 & 1250 \\
\hline $\mathrm{PM}(\mathrm{N} 38 \mathrm{SH})$ & 7400 & 8.923 & 502.3 \\
\hline Stator core (B35A300) & 7700 & 55.6 & 504 \\
\hline Rotor $(10 \#)$ & 7870 & 51.9 & 448 \\
\hline Inner/Outer air gap (vacuum) & 1.21 & As shown in Table 6 & 1005 \\
\hline
\end{tabular}
measuring instrument.

The thermal parameters of motor materials are shown in Table 7.

Table 7. Thermal parameter of motor materials. 


\subsection{Thermal Field Analysis under Natural Condition}

The thermal filed distribution of five DRPMSMs with different power levels is mainly analyzed under natural condition and the motors operate at the rated load and the rated speed. According to the Equation (24), the value of $v_{2}$ is considered to be zero under natural condition. Then, by applying the heat conduction coefficients to the correlative material and surfaces, and adding the heat sources to the corresponding parts, the 3-D thermal field distribution is obtained by the 3-D thermal FEM.

Taking a model of $1 \mathrm{~kW}$ DRPMSM as an example, temperature field distribution is analyzed under natural condition. The 3-D FEM graph of the mesh division and the temperature field distribution of $1 \mathrm{~kW}$ DRPMSM are shown in Figures 11 and 12, respectively. From Figure 12, the maximum temperature locates in the stator windings and the minimum temperature locates in the rotor. The temperature of PMs in inner motor is higher than that in outer motor because the small space in inner motor is disadvantage to dissipate the heat. Thus, the temperature distribution of PMs in inner motor is selected to monitor. The maximum temperature in stator windings of DRPMSM is about $70.1{ }^{\circ} \mathrm{C}$, which is much lower than the insulating class $\mathrm{H}$ of $180^{\circ} \mathrm{C}$. The maximum temperature in PMs is about $61.7^{\circ} \mathrm{C}$, which is also lower that the PMs working temperature of $150^{\circ} \mathrm{C}$. Therefore, the motor can run safely for a long time under natural condition at the rated load and the rated speed.

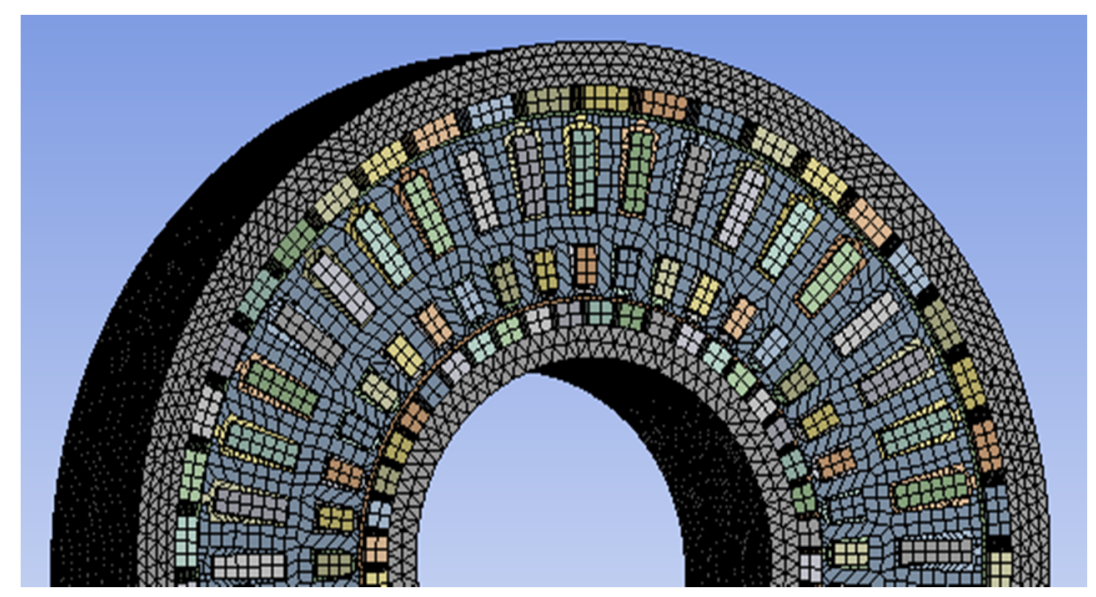

Figure 11. The three-dimension (3-D) graph of the mesh division of $1 \mathrm{~kW}$ DRPMSM.

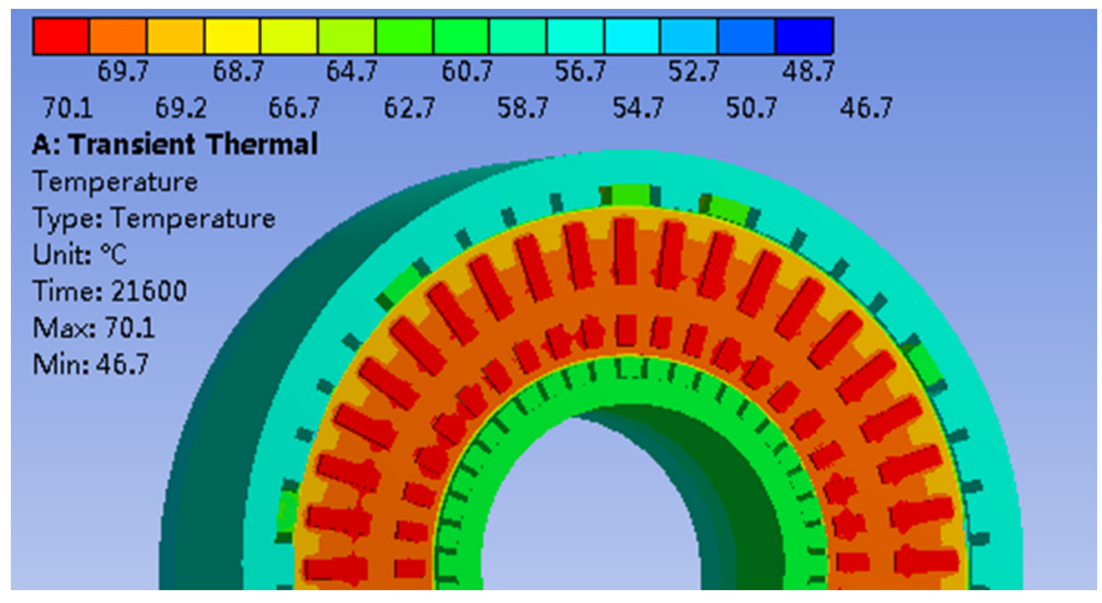

Figure 12. The temperature field distribution of $1 \mathrm{~kW}$ DRPMSM. 
Similarly, temperature waveforms of stator windings and PMs for five motors with different power level under natural conditions are obtained and shown in Figure 13. From Figure 13, it can be found that the temperature in stator windings and PMs increases within a certain period firstly, and then tends to dynamic equilibrium. The highest temperature in the stator windings of $1,5,10,20$, and $70 \mathrm{~kW}$ motors under natural condition are about 70.1, 91.50, 101.91, 170.47, and $211.31{ }^{\circ} \mathrm{C}$, which are all lower than the temperature limitation of the class $\mathrm{H}$ insulation except the motor of $70 \mathrm{~kW}$. The temperature in PMs are about $61.7,77.15,89.64,126.64$, and $184.39^{\circ} \mathrm{C}$, which are all lower than the PMs working temperature of $150{ }^{\circ} \mathrm{C}$ except the motor of $70 \mathrm{~kW}$. Therefore, the first four power level DRPMSMs can run safely for a long time under natural condition.

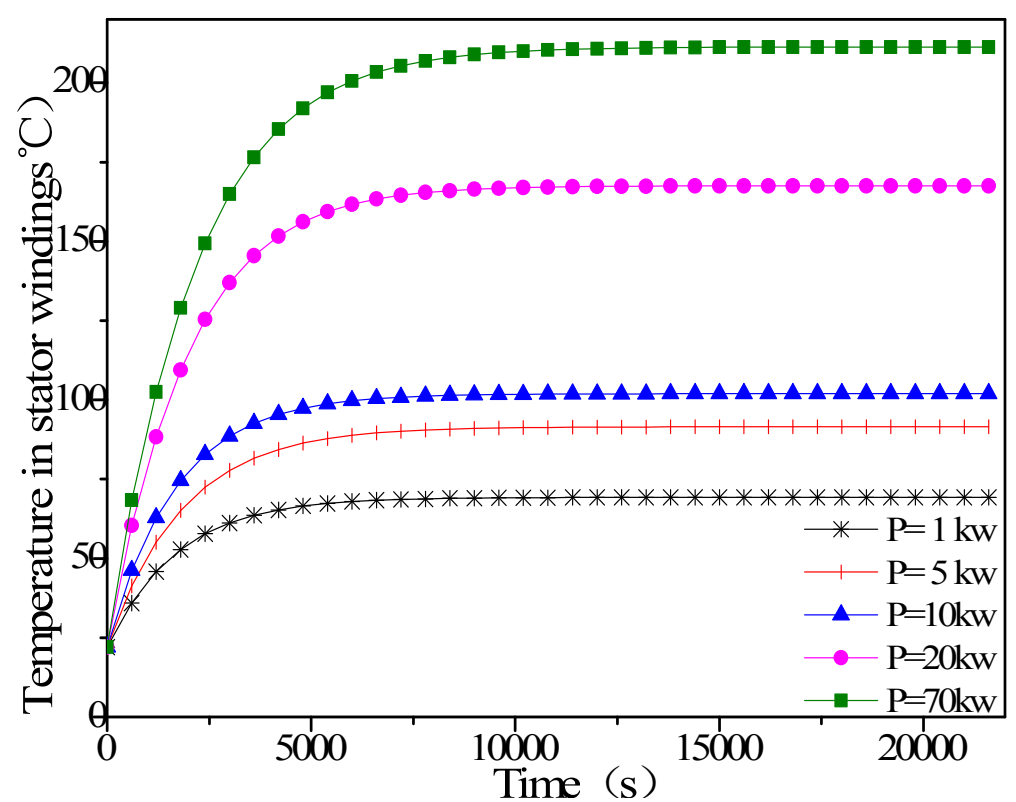

(a)

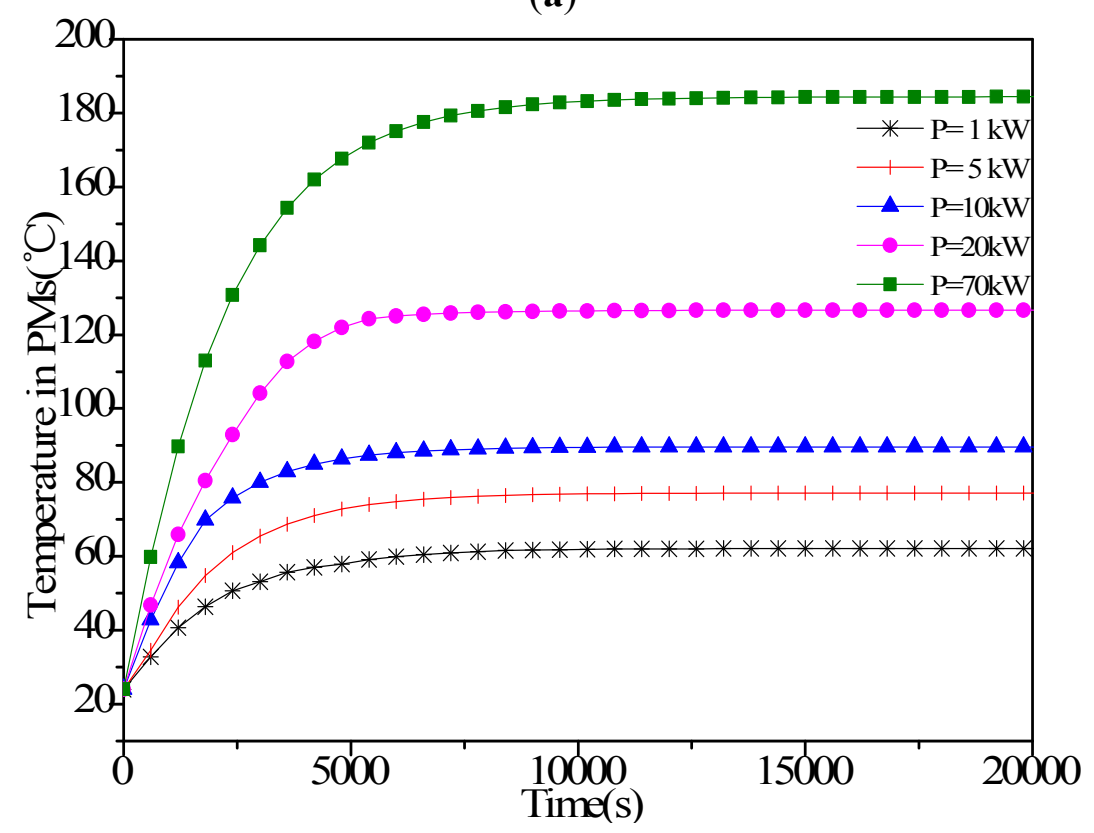

(b)

Figure 13. Temperatures versus time under natural condition: (a) in stator windings; and (b) in PMs. 


\subsection{Thermal Field Analysis under Forced-Air Cooling with Different Wind Speeds}

For $70 \mathrm{~kW}$ DRPMSM, the maximum temperature under natural condition is higher than the class $\mathrm{H}$ insulation, which is disadvantageous to operate at the rated load and rated speed for long time under natural condition. Therefore, applying different wind speeds to the outer surface of DRPMSM is researched. The influence of different wind speeds from $5 \mathrm{~m} / \mathrm{s}$ to $40 \mathrm{~m} / \mathrm{s}$ at the step of $5 \mathrm{~m} / \mathrm{s}$ are analyzed. In addition, the simulation results are shown in Figure 14. As can be seen from Figure 14, the DRPMSMs' temperatures in stator windings and PMs drop fast firstly and then tardily with the wind speed increasing. Therefore, it can be concluded that an effective wind speed has a great influence on the highest temperature of motors.

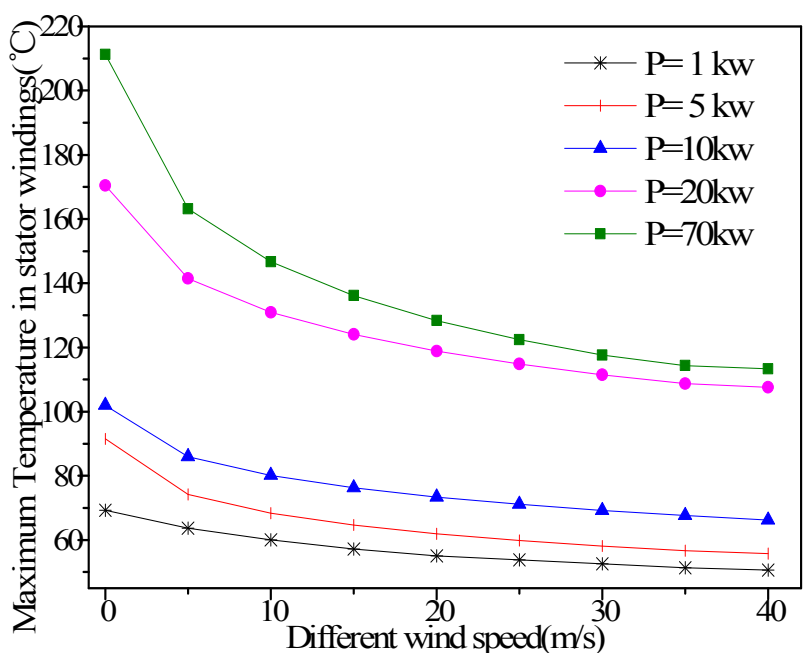

(a)

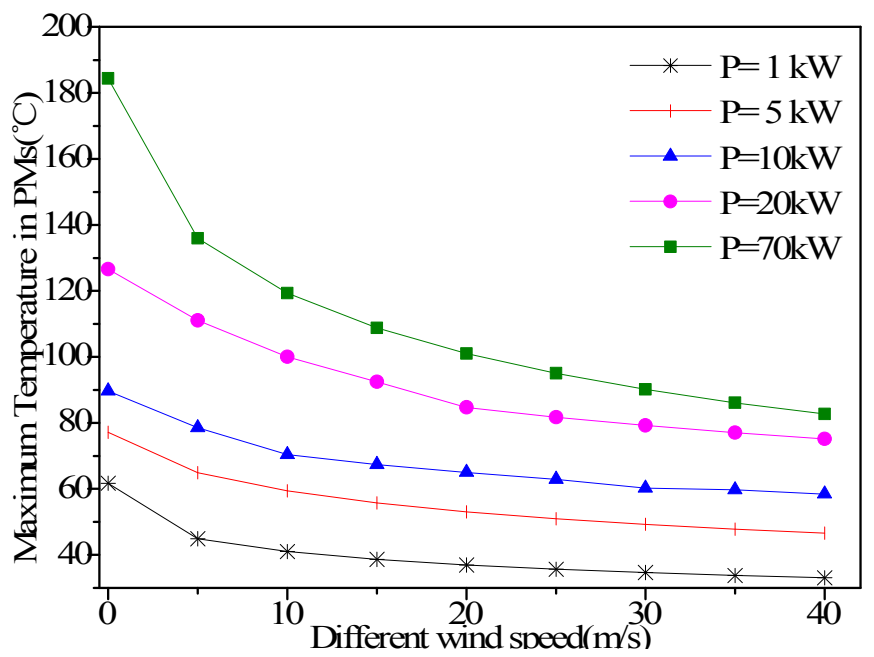

(b)

Figure 14. The maximum temperatures versus different wind speed: (a) in stator windings; and (b) in PMs.

\section{Mechanical Characteristic Analysis of the Dual-Rotor Permanent-Magnet Synchronous Motor (DRPMSM)}

In PMSM, the strong electromagnetic force containing the tangential and normal electromagnetic force exists between the stator teeth and the rotor PMs, which directly leads to mechanical deformation and vibration of stator. Especially for DRPMSM with nested stator, the normal electromagnetic force is one of the most important reasons to cause the vibration and noise due to the cantilever structure. Thus, electromagnetic force, the stress density and mechanical deformation of stator, under the conditions of no load and different loads, are researched and discussed in this section.

\subsection{The Normal Electromagnetic Force Calculation}

Nowadays, many methods such as the analytical method and the finite element method are used to calculate the electromagnetic force. In this paper, the finite element method is selected. Firstly, the normal and tangential density of air gap can be obtained by the 2-D FEM, and then the electromagnetic force is calculated by the Maxwell stress tensor method. 
A point in the air gap is selected to illustrate the normal and tangential flux density of air gap, as shown in Figure 15.

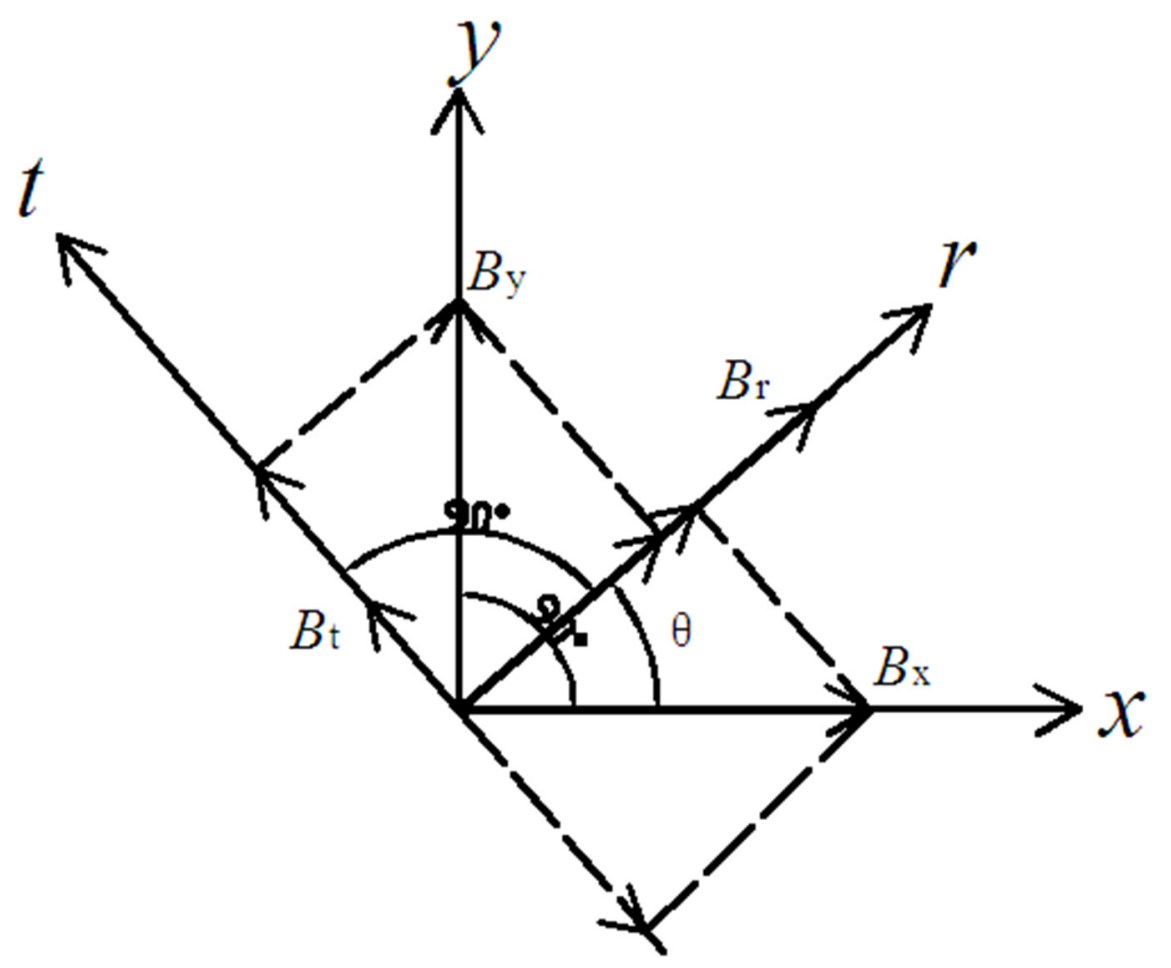

Figure 15. Calculation of normal and tangential flux density in the air gap.

Therefore, the normal flux density of air gap is expressed as:

$$
B_{\mathrm{n}}=B_{x} \cos \theta+B_{y} \sin \theta
$$

The tangential flux density of air gap is calculated by:

$$
B_{\mathrm{t}}=-B_{x} \sin \theta+B_{y} \cos \theta
$$

where $B_{\mathrm{n}}$ is the normal flux density of air gap; $B_{\mathrm{t}}$ is the tangential flux density of air gap; $B_{x}$ is the flux density of $X$ axial component; $B_{y}$ is the flux density of $Y$ axial component; $\theta$ is the angle of cylindrical coordinate.

According to the Maxwell Stress Tensor method, the normal electromagnetic force per unit area is obtained by:

$$
f_{\mathrm{n}}=\left(B_{\mathrm{n}}^{2}-B_{\mathrm{t}}^{2}\right) /\left(2 \mu_{0}\right)
$$

where $f_{\mathrm{n}}$ is the normal electromagnetic force density; $B_{\mathrm{n}}$ and $B_{\mathrm{t}}$ are the normal and tangential flux density of air gap, respectively; $\mu_{0}$ is the permeability of vacuum, $\mu_{0}=4 \pi \times 10^{-7}$.

As the DRPMSM is operating, different positions in the air gap have different flux densities, which results from different normal electromagnetic force density according to the Equation (27). An example of $1 \mathrm{~kW}$ DRPMSM is selected to calculate the normal electromagnetic force density in inner and outer air gap and it works at the rated current and the rated speed. The results are shown in Figure 16. 


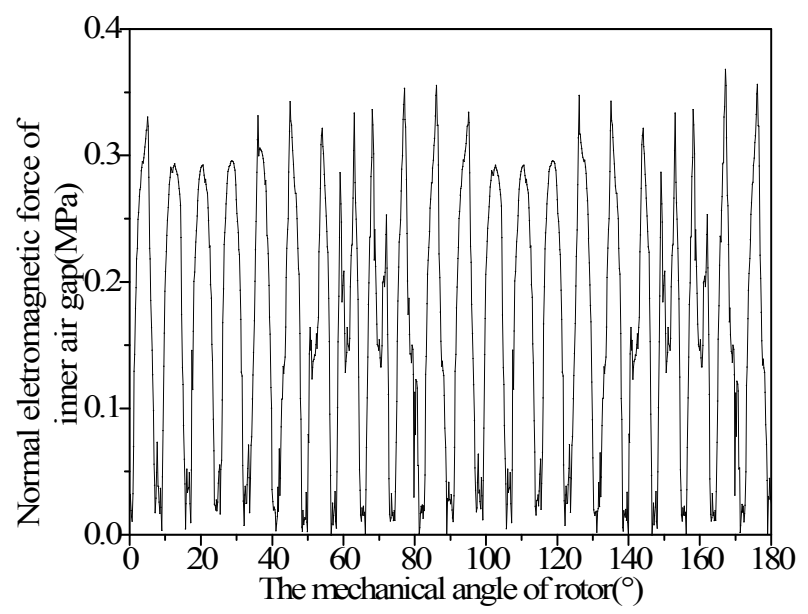

(a)

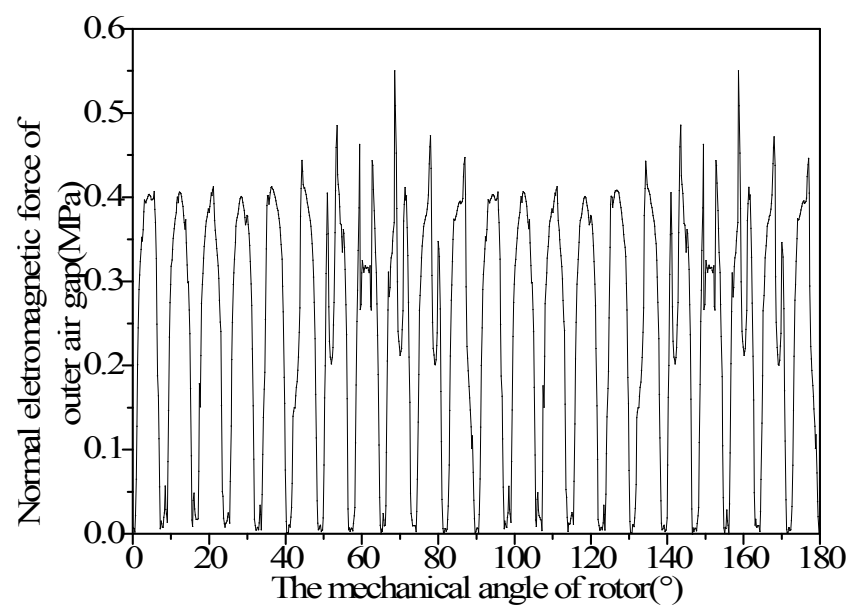

(b)

Figure 16. The normal electromagnetic force density of 1 kW DRPMSM: (a) inner air gap; and (b) outer air gap.

As can be seen from Figure 16, different stator position has different normal electromagnetic force density. In order to make the mechanical characteristic more reasonable, the maximum value of normal electromagnetic force density is selected to be researched. The maximum electromagnetic force density in the inner and outer air gap for five different power levels DRPMSMs under different load conditions are shown in Figure 17.

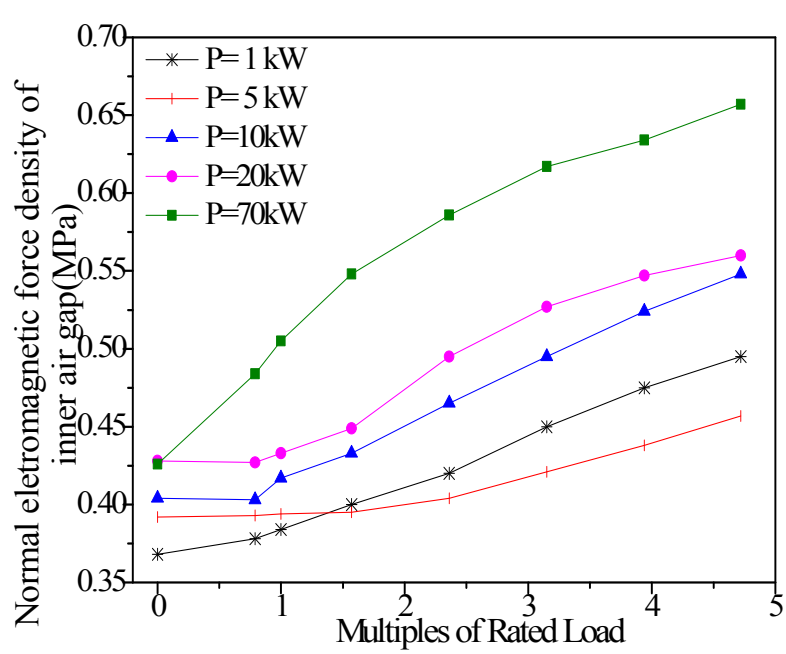

(a)

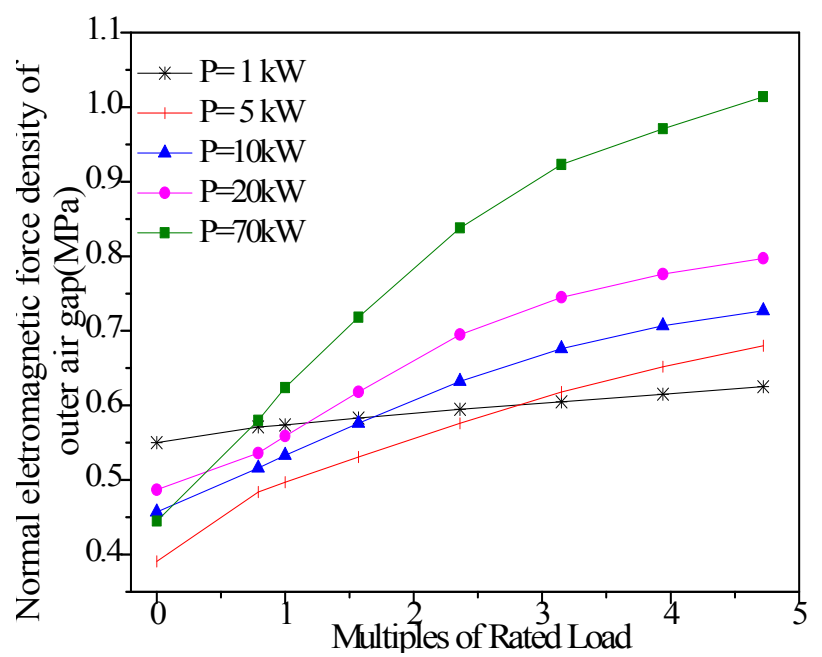

(b)

Figure 17. The maximum normal electromagnetic force density of five different power level DRPMSMs: (a) inner air gap; (b) outer air gap.

Through Figure 17, it can be found that the normal electromagnetic force density in the inner and outer air gaps become larger as the load increases. Comparing the data in Figure 17a, it can be seen that the electromagnetic force densities in the inner air gap almost have no change when the current multiple is between 0 and 0.8 and increase fast when the multiple is beyond 0.8 . Figure $17 \mathrm{~b}$ indicates that the electromagnetic force densities in the outer air gap increase quickly at first and then slowly. 
4.2. The Mechanical Characteristic of Dual-Rotor Permanent-Magnet Synchronous Motor (DRPMSM) under No-Load Condition

An example of $1 \mathrm{~kW}$ DRPMSM stator model is selected to research deformation and stress density of stator under no-load condition. The 3-D graph of the mesh division is shown in Figure 18. Firstly, the maximum values of normal electromagnetic force density for the inner and outer surface of stator are calculated by Equation (27), whose values are $0.36 \mathrm{MPa}$ and $0.55 \mathrm{MPa}$. Then, the maximum values are applied to the corresponding surfaces of stator. The distribution of deformation and stress density of stator are shown in Figure 19.

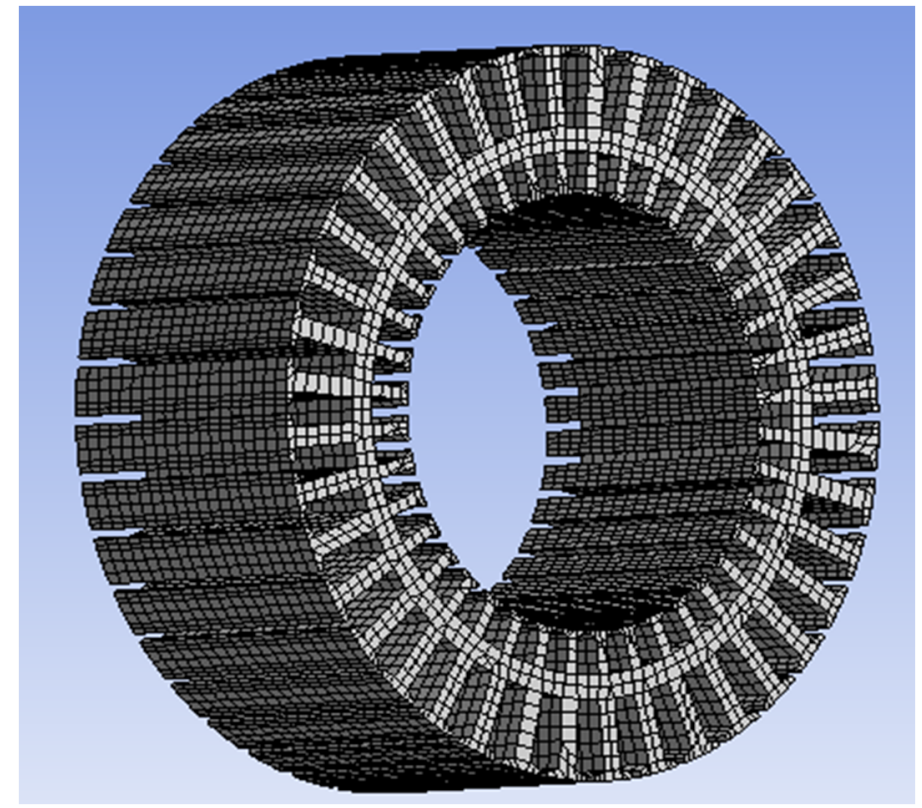

Figure 18. Mesh partition of stator of $1 \mathrm{~kW}$ DRPMSM.

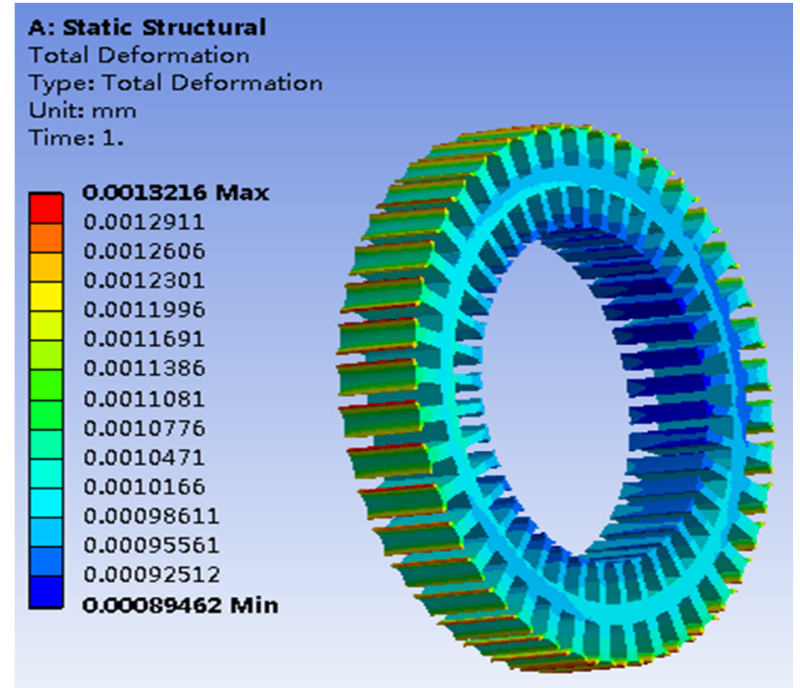

(a)

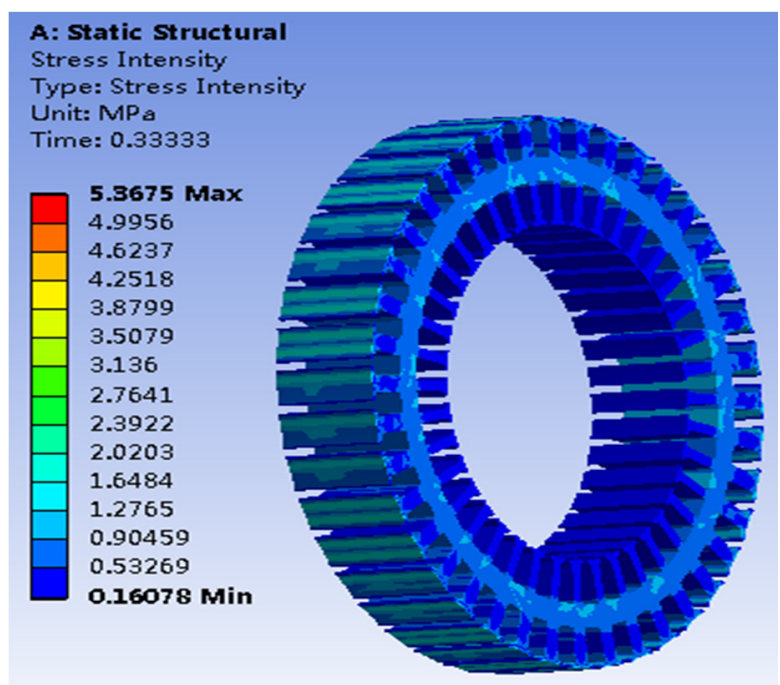

(b)

Figure 19. The stator of $1 \mathrm{~kW}$ DRPMSM: (a) deformation; and (b) stress density distribution. 
From the Figure 19, it can be obtained that the maximum deformation of stator is $0.00132 \mathrm{~mm}$. The maximum stress density is $4.8642 \mathrm{MPa}$, which is much less than the maximum bearing stress density of $250 \mathrm{MPa}$ for material B35A300.

Similarly, the stress density of stator for the $5 \mathrm{~kW}, 10 \mathrm{~kW}, 20 \mathrm{~kW}, 70 \mathrm{~kW}$ DRPMSMs under no load condition are 5.91 MPa, 6.21 MPa, 13.27 MPa and 38.1 MPa, respectively, which are all much less than the maximum bearing stress density of stator material B35A300 and can operate safety.

\subsection{The Mechanical Characteristic under Different Load Condition}

The normal electromagnetic force of stator is much influenced by different loads. The deformation and stress density of stator are analyzed and compared under different loads conditions. The maximum deformation and maximum stress density of stator are obtained and shown in Figure 20.

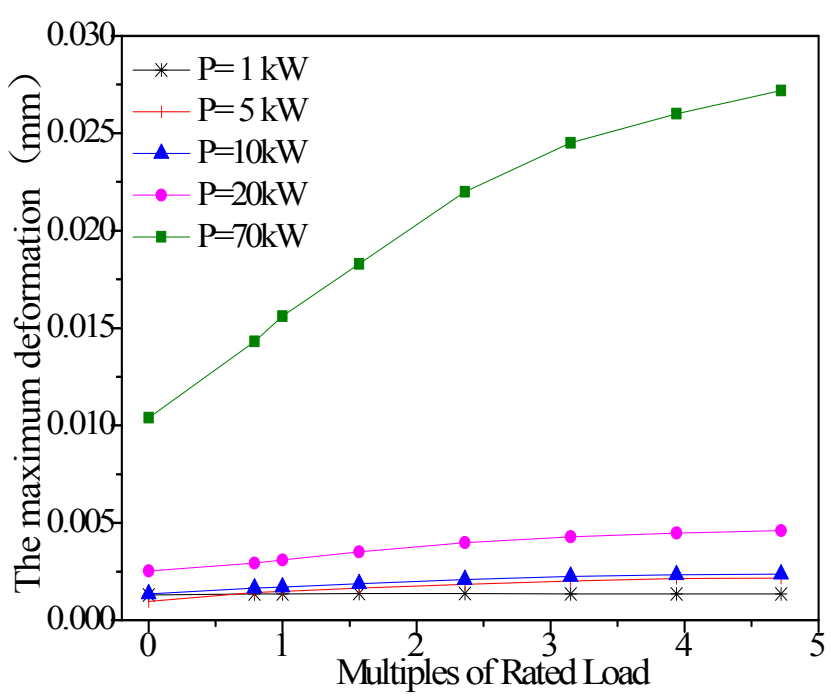

(a)

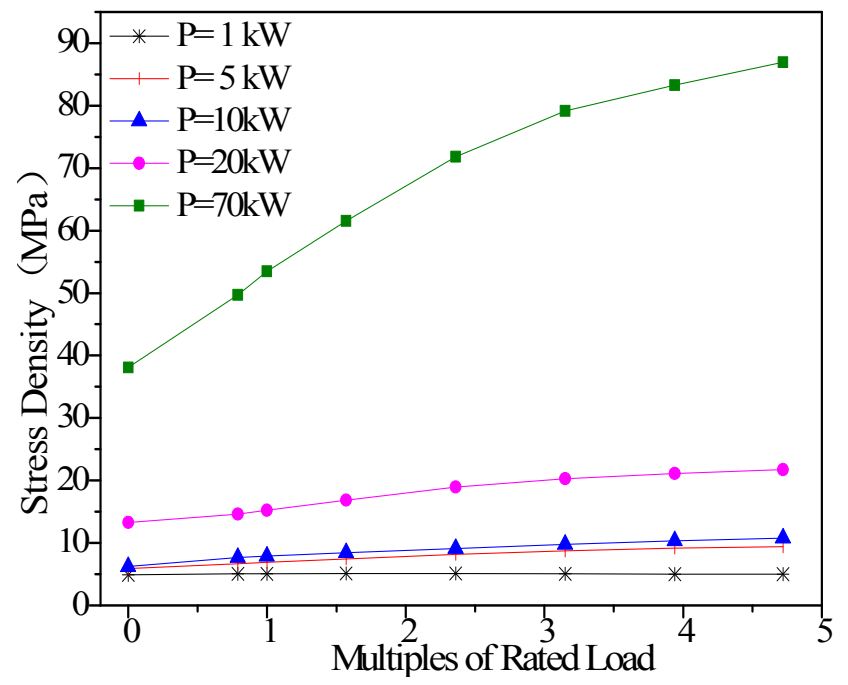

(b)

Figure 20. The stator of five different power level DRPMSMs: (a) deformation; and (b) stress density.

According to the changing tendency of five different power level DRPMSMs in Figure 20, the stator's deformation and stress density increase as the current increases. As for $1 \mathrm{~kW}, 5 \mathrm{~kW}, 10 \mathrm{~kW}$, and $20 \mathrm{~kW}$ DRPMSMs, their deformations and stress densities change slowly with the current increasing. However, $70 \mathrm{~kW}$ DRPMSM changes dramatically. Especially for $70 \mathrm{~kW}$, the highest stress density is $86.95 \mathrm{MPa}$ and the maximum deformation is $0.0272 \mathrm{~mm}$ when the load is 4.72 times rated load. Therefore, middle and small power level DRPMSMs is preferred for safely running with a high current.

\section{Discussion of Calculated Results}

Five different power level DRPMSMs of 1, 5, 10, 20 and $70 \mathrm{~kW}$ are selected to investigate their electromagnetic, thermal and mechanical characteristics in this paper.

The main ratio of $k$ is optimized to obtain the optimal performances such as the highest power density, the highest average torque, the lowest mass and so on. The highest power density is achieved 
around the ratio of 0.4 and all power levels have the same variation as the ratio of $k$ changes. With the power level increasing, the power density and efficiency increases quickly. Based on the research of power density, it is better to select high power level to obtain higher power density and high efficiency. However, high power level motors will generate more losses, which cause high temperature of the motor. Higher temperature is disadvantageous for DRPMSM to run safely under natural condition. Based on the thermal distribution under natural condition, middle and small power level are more suitable. In this paper, forced-air cooling with different wind speeds is applied on the outer surface of motor to reduce the temperature. However, an effective forced-air cooling system could allow a high power level motor to run safely. The stator's deformation and stress density increase as the load increases. As for small and middle power levels, the deformation and stress density have a small change as the load increases. For high power level, they increase quickly with the load increasing. The stress density easily reaches the maximum bearing stress density of stator and it is harmful for motor to operate.

In general, with the power level increasing, the power density, the temperature rise, deformation and stress density of stator all increase. A high-power level motor needs harsh cooling system to insure the safely temperature rise. In addition, the result of mechanical characteristic indicates that high power level is easy to exceed the safely mechanical strength. Therefore, a tradeoff is necessary. Middle and small power level is more preferable selection for this kind of structure to run safely.

\section{Experiments}

\subsection{The Dual-Rotor Permanent-Magnet Synchronous Motor (DRPMSM) Prototype}

A prototype DRPMSM with rated power of $1 \mathrm{~kW}$ and rated speed of $600 \mathrm{rpm}$ is manufactured to validate the simulation results, as shown in Figure 21.

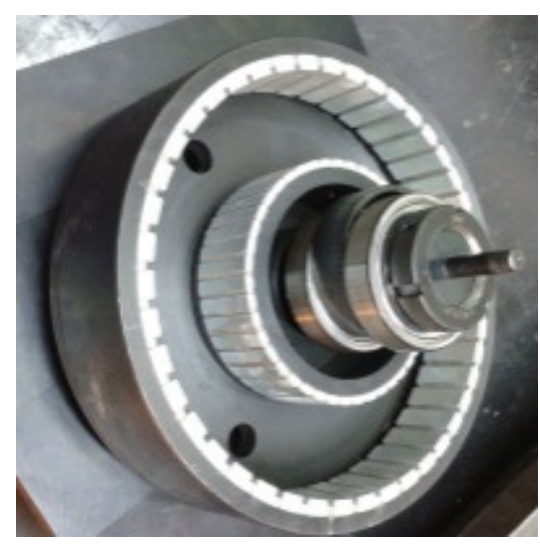

(a)

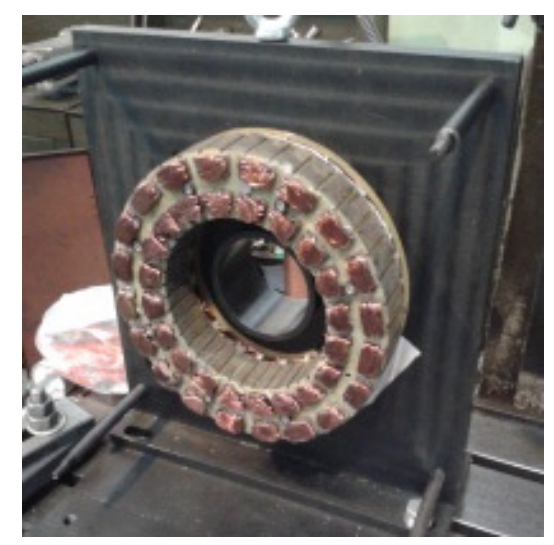

(b)

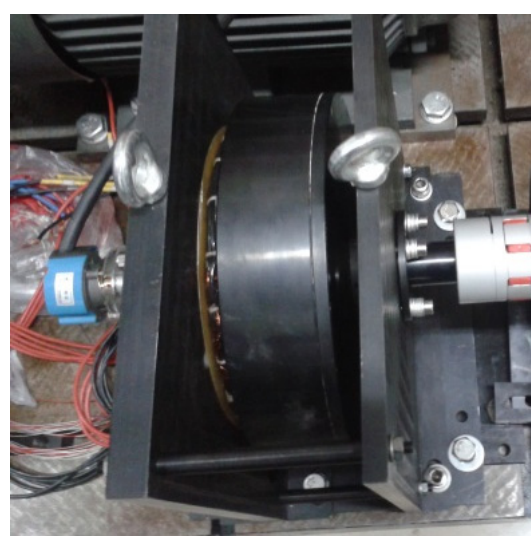

(c)

Figure 21. Main components of DRPMSM prototype: (a) rotor; (b) stator; and (c) prototype.

\subsection{The Electrical Parameters Measurement}

The measuring instrument of LCR- 821 meter is used to measure the phase resistance and inductance of the inside and outside winding as shown in Figure 22. The ambient temperature is $24{ }^{\circ} \mathrm{C}$ and the results of obtained by FEM and experiment are displayed in Tables 8 and 9. 


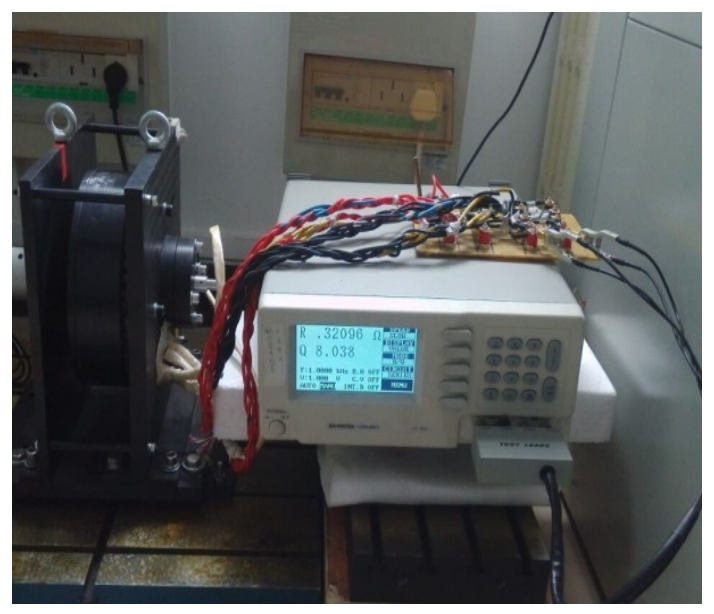

Figure 22. Measuring instrument of resistance and inductance by LCR-281meter.

Table 8. The measured and calculated phase resistance of DRPMSM.

\begin{tabular}{ccccccc}
\hline Position & \multicolumn{4}{c}{ Measured resistance $(\mathbf{m} \boldsymbol{\Omega})$} & & Calculated resistance (m $\mathbf{)})$ \\
\hline Phase & A & B & C & D & E & A, B, C, D, E \\
\hline Outside winding & 321 & 321.8 & 326.2 & 329 & 325.7 & 319 \\
Inside winding & 335.3 & 337.2 & 338.5 & 339.2 & 337.8 & 330 \\
\hline
\end{tabular}

Table 9. The measured and calculated phase inductance of DRPMSM.

\begin{tabular}{llccccc}
\hline & Phase & A & B & C & D & E \\
\hline \multirow{2}{*}{ Outside winding } & Measured inductance $(\mu \mathrm{H})$ & 759.5 & 759 & 761.6 & 758.3 & 753.6 \\
& Calculated inductance $(\mu \mathrm{H})$ & 765.4 & 766.4 & 765.9 & 765.9 & 766.3 \\
\hline \multirow{2}{*}{ Inside winding } & Measured inductance $(\mu \mathrm{H})$ & 780.5 & 782.6 & 785.4 & 782.8 & 778.8 \\
& Calculated inductance $(\mu \mathrm{H})$ & 752.6 & 753.7 & 755.4 & 753.7 & 752.9 \\
\hline
\end{tabular}

According to the results of Tables 8 and 9, the measured resistances are close to the calculated values with the maximum error of $3.1 \%$ and the measured inductances are similar to the calculated values with the maximum error of $4.0 \%$. The comparison results indicate that the calculated and measured parameters are in good agreement.

\subsection{The No-Load Back Electromotive Force (EMF) Experiment}

A DC motor is selected to drive the DRPMSM rotation at no load. The no-load back EMFs of inner and outer motor at the speed of $200 \mathrm{rpm}$ is measured and shown in Figure 23. According to the Figure 23, it can be seen that the measured back EMFs of inner and outer motor well match the design ones, which validate a good electromagnetic design of the motor.

\subsection{The Load Experiment}

Two sets of windings (inside winding and outside winding) are installed in the inside and outside stator slots and they are serially connected. The drive circuit is shown in Figure 24.

In the experiment, the DRPMSM operates at low speed and outputs low torque. The magnetic powder brake is used as the load. A high-precision speed/torque sensor is used to measure the output 
torque and steady-state speed at load. The test platform is shown in Figure 25 and the measured results are shown in Figure 26.

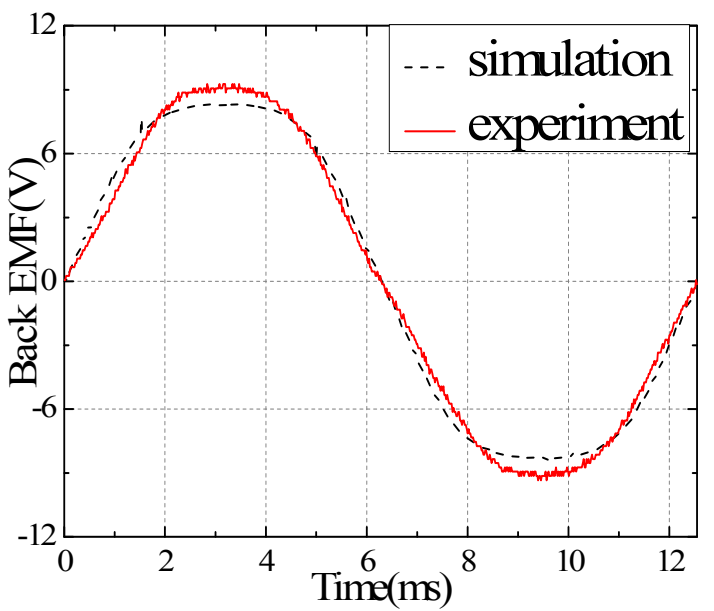

(a)

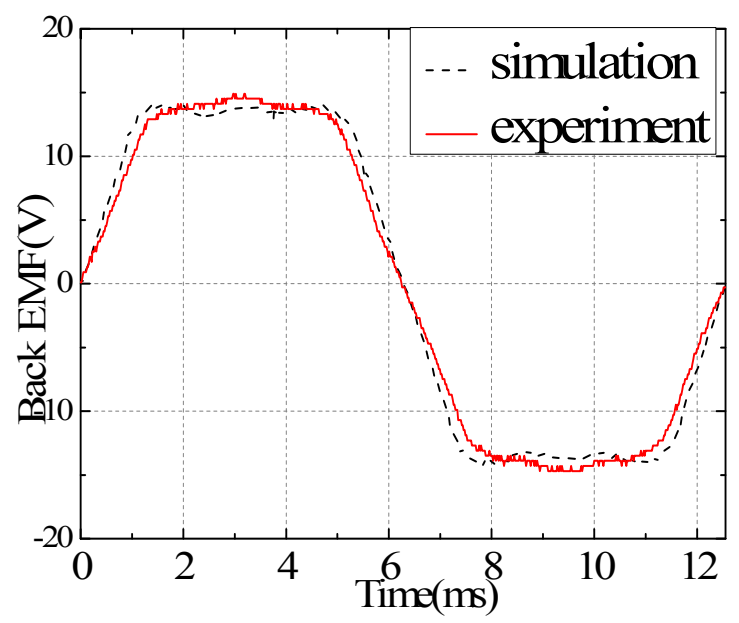

(b)

Figure 23. No-load Back EMF in (a) inner motor; and (b) outer motor.

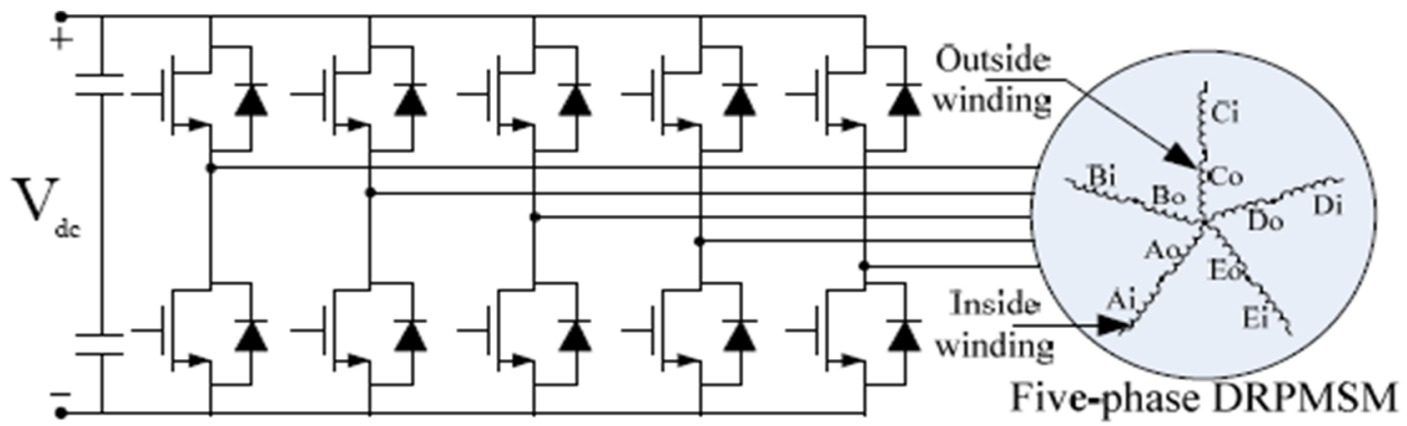

Figure 24. The drive circuit of DRPMSM.

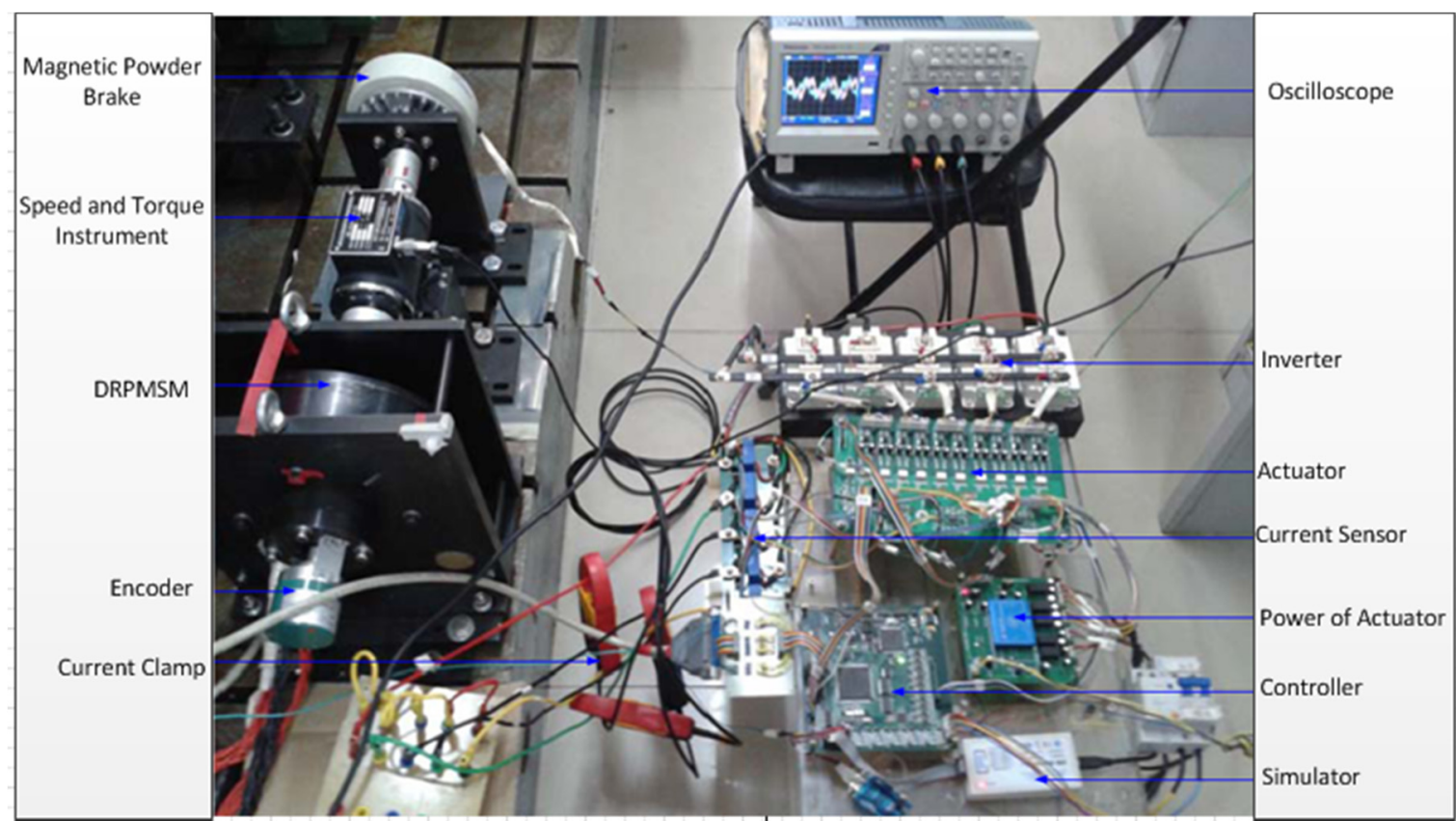

Figure 25. Test platform of DRPMSM. 


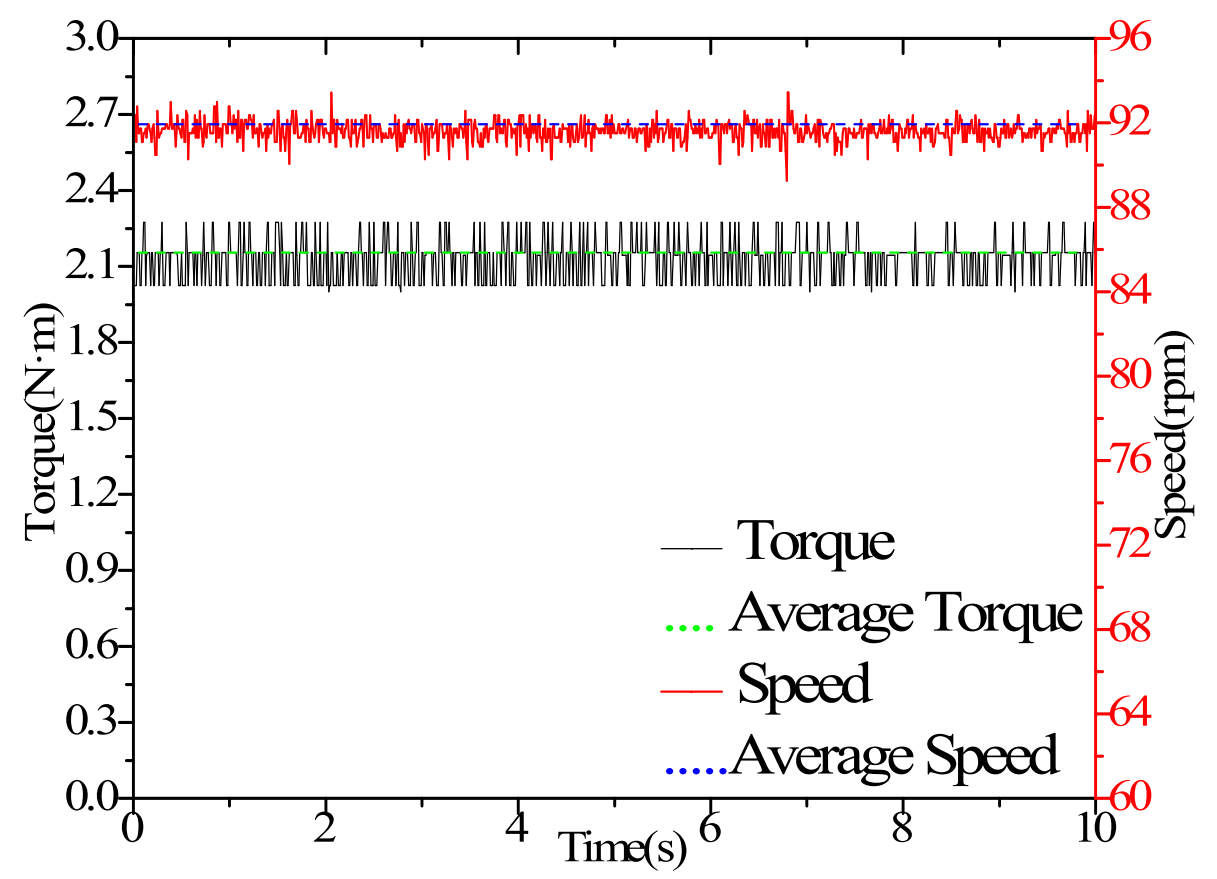

Figure 26. The average output torque and steady-state speed of 1 kW DRPMSM.

The measured average torque and steady-state speed at load are about $2.1 \mathrm{~N} \cdot \mathrm{m}$ and $92 \mathrm{rpm}$, respectively. The measured torque ripple is about $12.8 \%$, which is a little higher than that by the FEM of $9.42 \%$. One reason is that: the simulated value is obtained by applying a sinusoidal current to motor. In the actual tests, PWM wave is applied to the motor and test current waveform is shown in Figure 27. Only three channel oscilloscopes are obtained in the lab, so the current waveforms of A, B and C are tested. From the Figure 27, it can be found that the current harmonic is larger than that by the FEM. This will cause the motor to vibrate. Another reason is that the load is produced by the magnetic powder brake, which cannot produce steady load and its ripple will superpose on the tested machine.

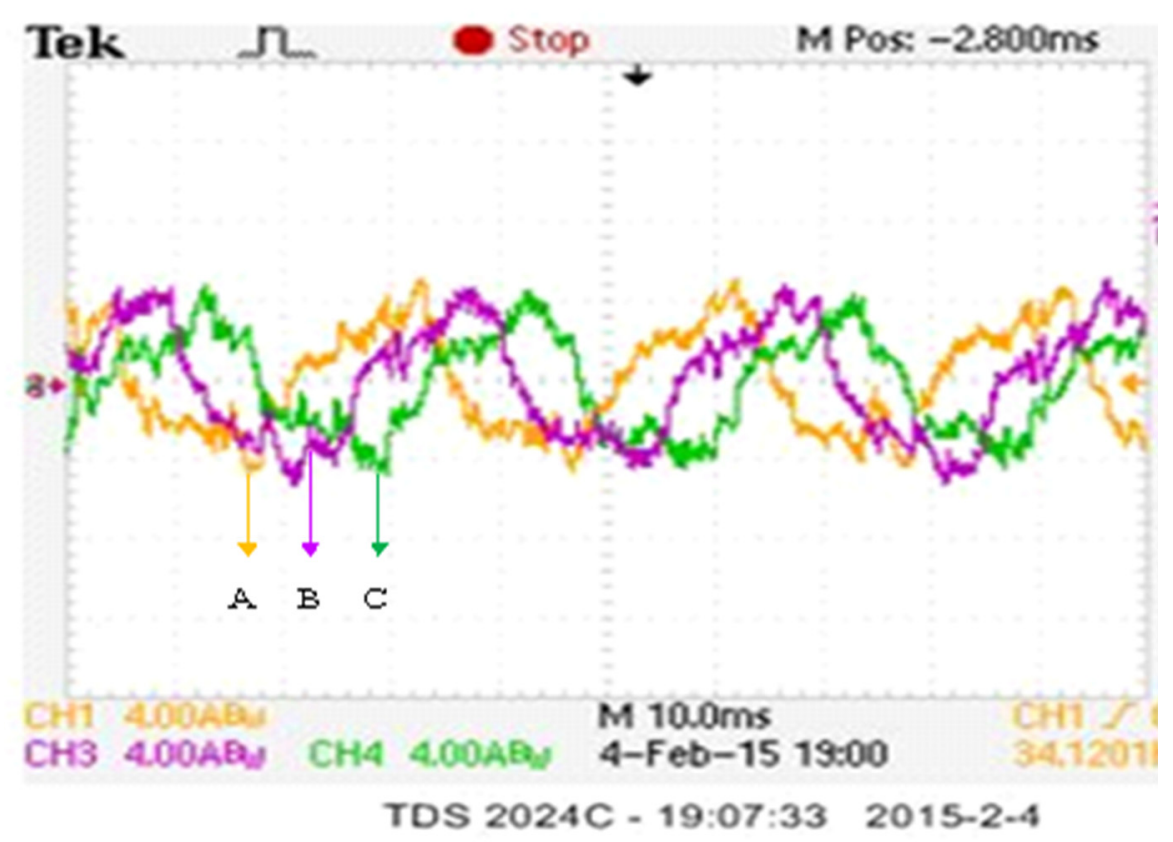

Figure 27. The measured current waveform of $1 \mathrm{~kW}$ DRPMSM. 


\subsection{The Thermal Experiment}

When the DRPMSM is operating at the load of $2.1 \mathrm{~N} \cdot \mathrm{m}$ and the speed of $92 \mathrm{rpm}$. The transient state analysis is performed on a $21,600 \mathrm{~s}$ interval and the ambient temperature is considered to be $24{ }^{\circ} \mathrm{C}$.

Ten thermistors of PT100 are embedded in the inside and outside slots to measure the temperature distribution of stator windings. The positions of thermistors are as shown in Figure 28. Then, the thermistor is connected to the temperature measuring instrument. Due to the limited number of temperature measuring instruments, only the temperature of $\mathrm{A}$ and $\mathrm{B}$ phase windings of inner motor and outer motor are measured in this paper, as shown in Figure 29.

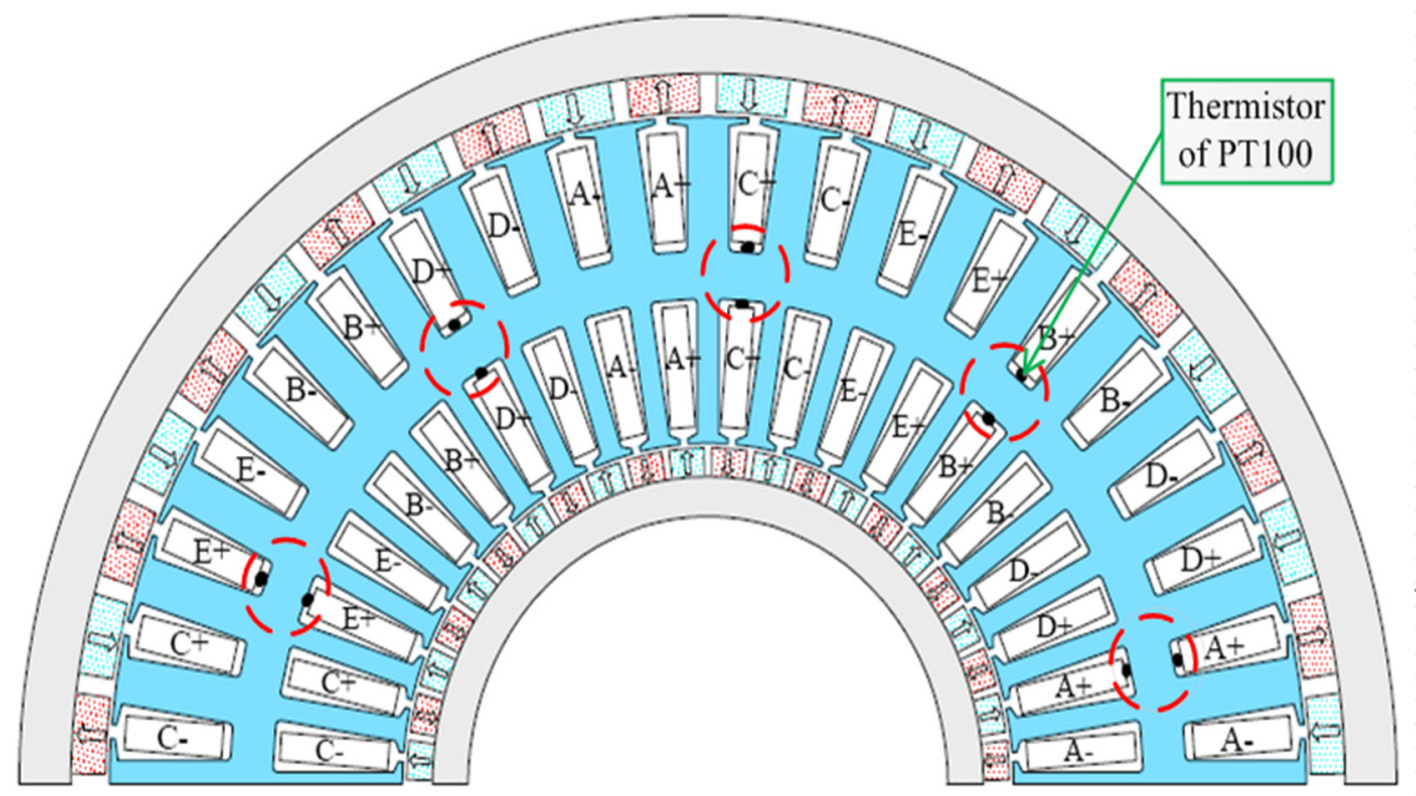

Figure 28. The positions of thermistors.

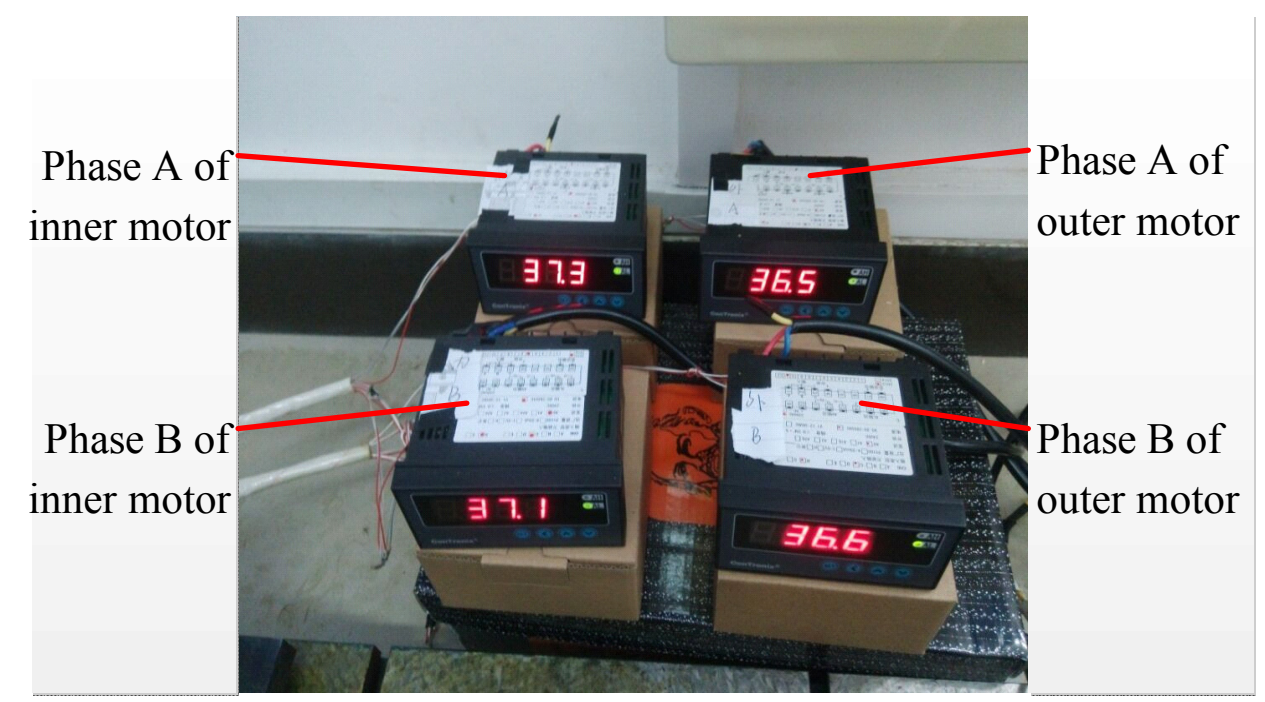

Figure 29. The temperature measuring instruments.

Under natural condition, the simulated steady-temperature in the slot of the machine by Ansys is about $37.5^{\circ} \mathrm{C}$. The experiment results of phase A and B for inner motor are about $38.2{ }^{\circ} \mathrm{C}, 37.8^{\circ} \mathrm{C}$ and 
that of outer motor are about $37.0^{\circ} \mathrm{C}, 37.4^{\circ} \mathrm{C}$, as shown in Figure 30. Because the outer motor is more easily affected by the surrounding environment, so the measured temperatures of outer motor are a little lower than that of inner motor. Comparing the simulated and measured results, the maximum error is about $0.7^{\circ} \mathrm{C}$, the main reasons may be the effect of surrounding environment, the calculated error of different parts of the transfer coefficient, the error measuring instrument and so on. However, the temperature trends are consistent in general, and it validates the simulated method and calculated results credibly. Both the measured and simulated results indicate that the DRPMSM prototype can work safely under natural condition.

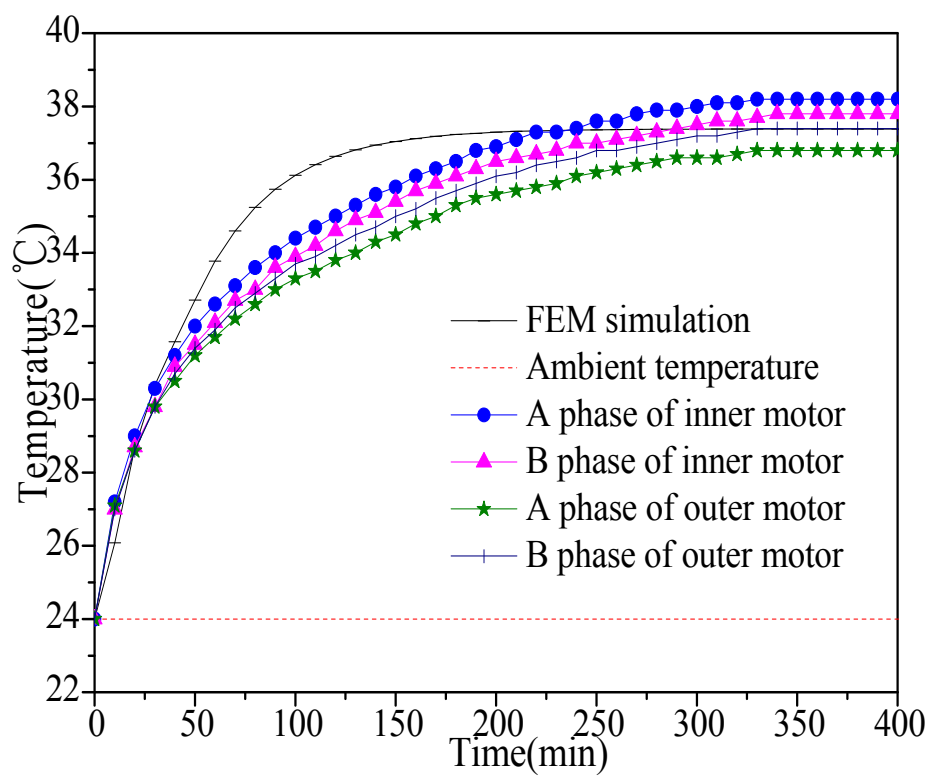

Figure 30. The measured and simulated temperature distribution.

\section{Conclusions}

(1) In this paper, three aspects of five different power levels of Five-Phase DRPMSMs are investigated, which contain electromagnetic, thermal and mechanical characteristics.

(2) The electromagnetic characteristic is analyzed by 2-D FEM. When the ratio of length to diameter is around 0.4 , the machine obtains the highest power density, highest output average torque and highest power versus active mass and the lowest active mass. The total loss decreases as the ratio $k$ increases. The highest efficiency is achieved around 0.8 of the ratio. At certain ratio, the power density and efficiency increase with the power level increasing.

(3) Concerning the thermal characteristic, 3-D thermal models are adopted. Under natural condition, the lower power level DRPMSM can run safely at rated load and rated speed, but it is dangerous for high power level running at rated load and rated speed. The influence law of the wind speed on the temperature rise of DRPMSM is researched and obtained. Wind velocity makes a great contribution to the heat dissipation of motor. Different power levels have different requirements for wind velocity. The temperature rise increases with the power level increasing in the same circumstance. When wind with high speeds are used in the surface of high power level DRPMSM, it can run safely at rated load and rated speed. This provides a reference for the design of the forced air cooling system. 
(4) The deformation and stress density of stator are considered and analyzed by the 3-D FEM models. Due to the cantilever structure, deformation and stress density of stator increases with the power level increasing at the same load. The middle and small power level DRPMSMs can run safely under the different conditions, whose deformation and stress density almost have no change with different load.

(5) A principle of selecting power level for this kind of structure motor is obtained with comprehensively considering the power density, thermal and mechanical characteristics of DRPMSM.A tradeoff is adopted. Middle and small power level is more preferable selection for this kind of structure to run safely.

(6) A $1 \mathrm{~kW}$ DRPMSM prototype is manufactured. The phase resistance, phase inductance, back EMFs at no load, torque characteristic at load and temperature rise are measured and compared with the simulated results, which validates the FEM model and calculation method.

\section{Acknowledgments}

This work was supported in part by the National Natural Science Foundation of China under Project 51307008 and 51347009, in part by Ph.D. Programs Foundation of Ministry of Education of China under Project 20121101120024, in part by Basic Research Foundation of Beijing Institute of Technology under Grant 20110642015, 20120642013and 20130642015, and in part by Excellent Young Scholars Research Fund of Beijing Institute of Technology.

\section{Author Contributions}

All authors contributed to this work by collaboration. Jing Zhao is the main author of this manuscript. Wei Liu assisted to establish the finite element model of five-phase DRPMSM and perform the simulations. Bin Li, Xiangdong Liu, Congze Gao, and Zhongxin Gu provided some useful suggestions in the construction of paper. All authors revised and approved the publication.

\section{Conflicts of Interest}

The authors declare no conflict of interest.

\section{References}

1. Chau, K.T.; Chan, C.C. Emerging energy-efficient technologies for hybrid electric vehicles. IEEE Proc. 2007, 95, 821-835.

2. Chau, K.T.; Chan, C.C.; Liu, C. Overview of permanent-magnet brushless drives for electric and hybrid electric vehicles. IEEE Trans. Ind. Electron. 2008, 55, 2246-2257.

3. Pellegrino, G.; Vagati, A.; Boazzo, B.; Guglielmi, P. Comparison of induction and PM synchronous motor drives for EV application including design examples. IEEE Trans. Ind. Appl. 2012, 48, 2322-2332.

4. Zhu, Z.Q.; Howe, D. Electrical machines and drives for electric, hybrid and fuel cell vehicles. IEEE Proc. 2007, 95, 746-765. 
5. Igelspacher, J.; Herzog, H.G. Analytical description of a single-stator axial-flux induction machine with squirrel cage. In Proceedings of the International Conference on Electrical Machines (ICEM), Rome, Italy, 6-8 September, 2010; pp. 1-6.

6. Nasiri-Gheidari, Z.; Lesani, H. New design solution for static eccentricity in single stator-single rotor axial flux induction motors. IET. Electr. Power Appl. 2013, 7, 523-534.

7. Kano, Y.; Tonogi, K.; Kpsaka, T.; Matsui, N. Torque-maximizing design of double-stator, axial-flux, PM machines using simple non-linear magnetic analysis. In Proceedings of the 42 IAS annual meeting on Industry Applications Conference (IAC), New Orleans, LA, USA, 23-27 September 2007; pp. 875-881.

8. Nikolaj, Z.; Vladyslav, P.; Stanislav, F.; Jiri, L. Dynamic simulation of the double-stator induction electromagnetical converter with ferromagnetic rotor. In Proceedings of the 4th International Conference on Power Engineering Energy and Electrical Drives, Istanbul, Turkey, 13-17 May 2013; pp. 1448-1453.

9. Zhao, J.; Li, J.Q.; Chen, Z. Design and Analysis of a Five-Phase Double-Stator Permanent Magnet Synchronous Motor. In Proceedings of the International Conference on Electrical Machines and Systems (ICEMS), Hangzhou, China, 22-25 October 2014; pp. 967-973.

10. Zhang, Y.X.; Zhang, M.Y.; Ma, W.M.; Xu, J.; Lu, J.Y. Modeling of a double-stator linear induction motor. IEEE Trans. Energy Convers. 2012, 27, 572-579.

11. Qu, R.H.; Lipo, T.A. Dual-rotor, radial-flux, toridally-wound, permanent-magnet machines. IEEE Trans. Ind. Appl. 2003, 39, 1665-1673.

12. Li, Y.; Zhao, J.; Chen, Z.; Liu, X. Investigation of a Five-Phase Dual-Rotor Permanent Magnet Synchronous Motor Used for Electric Vehicles. Energies 2014, 7, 3955-3984.

13. Stegmann, J.A.; Kamper, M.J. Design aspects of double-sided rotor radial flux air-cored permanent-magnet wind generator. IEEE Trans. Ind. Appl. 2011, 47, 767-778.

14. Sinha, S.; Deb, N.K.; Mondal, N.; Biswas, S.K. Design and performance of a single stator, dual rotor induction motor. In Proceedings of the 7th International Conference on Power Electronics and Drive System (PEDS), Bangkok, Thailand, 27-30 November 2007; pp. 1163-1166.

15. Liu, Y.; Tong, C.D.; Bai, J.G.; Yu, S.; Tong, W.M.; Fu, W.N. Optimization of an $80 \mathrm{~kW}$ radial-radial flux compound-structure permanent-magnet synchronous machine used for HEVs. IEEE Trans. Magn. 2011, 47, 2399-2402.

16. Zheng, P.; Zhao, J.; Liu, R.R.; Tong, C.D.; Wu, Q. Magnetic characteristics investigation of an axial-axial flux compound-structure PMSM used for HEVs. IEEE Trans. Magn. 2010, 46, 2191-2194.

17. Popescu, M.; Jokinen, T.; Demeter, E.; Navrapescu, V. Magnetic materials in design and construction of electrical motors. In Proceedings of the 9th Mediterranean Electrotechnical Conference, Tel-Avic, Israel, 18-20 May 1998; pp. 125-128.

18. Sergeant, P.; Dupre, L. A non-destructive methodology for estimating the magnetic material properties of an asynchronous motor. IEEE Trans. Magn. 2012, 48, 1621-1624.

19. Sheth, N.K.; Rajagopal, K.R. Optimum pole arcs for a switched reluctance motor for higher torque with reduced ripple. IEEE Trans. Magn. 2003, 39, 3214-3216.

20. Kim, K.C.; Koo, D.H.; Hong, J.P.; Lee, J. A study on the characteristics due to pole-arc to pole-pitch ratio and saliency to improve torque performance of IPMSM. IEEE Trans. Magn. 2007, $43,2516-2518$. 
21. Chai, F.; Xia, J.; Gong, H.; Guo, B.; Cheng, S. Torque analysis of double-stator permanent magnet synchronous for hybrid electric vehicle. In Proceedings of the Vehicle Power and Propulsion Conference, Harbin, China, 3-5 September 2008; pp. 1-5.

22. Reichert, T.; Nussbaumer, T.; Kolar, J.W. Split ratio optimization for high-torque PM motors considering global and local thermal limitations. IEEE Trans. Energy Convers. 2013, 28, 493-501.

23. Chaaban, F.B. Determination of the optimum rotor/stator diameter ratio of permanent magnet machines. IEEE Trans. Electr. Mach. Power Syst. 1994, 22, 521-531.

24. Hideo, D.; Ishihara, Y.; Kaido, C.; Kchikara, Y.; Kitamura, S.; Shimomura, T.; Takahashi, N.; Yamada, T.; Yamazaki, K. Investigation of benchmark model for estimating iron loss in rotating machine. IEEE Trans. Magn. 2004, 40, 794-797.

25. Chu, W.Q.; Zhu, Z.Q.; Liu, X.; Stone, D.A.; Foster, M.P. Iron loss calculation in permanent magnet machines under unconventional operations. IEEE Trans. Magn. 2014, 50, 1-4.

26. Li, W.; Cao, J.; Zhang, X. Electrothermal analysis of induction motor with compound cage rotor used for PHEV. IEEE Trans. Ind. Electron. 2010, 57, 660-668.

27. Bai, J.G.; Liu, Y.; Sui, Y.; Tong, C.; Zhao, Q.; Zhang, J. Investigation of the cooling and thermal-measuring system of a compound-structure permanent-magnet synchronous machine. Energies 2014, 7, 1393-1426.

28. Sum, X.K.; Cheng, M. Thermal analysis and cooling system design of dual mechanical port machine for wind power application. IEEE Trans. Ind. Electron. 2013, 60, 1724-1733.

29. Li, C.; Pei, Y.; Ni, R.; Cheng, S. Analysis of 3D static temperature field of water cooling induction motor in mini electric vehicle. In Proceedings of the 2011 International Conference on Electrical Machines and Systems, Beijing, China, 20-23 August 2011; pp. 1-5.

30. Chen, H.; Wang, Y.G.; Zhao, Q.X.; Ma, H.D.; Li, Y.X.; Chen, Z.Y. Experiment investigation of heat transfer and pressure drop characteristics of H-type finned tube banks. Energies 2014, 7, 7094-7104.

31. Boglietti, A.; Cavagnino, A.; Staton, D.A.; Popescu, M. Impact of different end region cooling arrangements on endwinding heat transfer coefficients in electric motors. In Proceedings of the 35th Annual Conference on Industrial Electronics, Porto, Portugal, 3-5 November 2009; pp. $1168-1173$.

32. Kim, S.C. Thermal performance of motor and inverter in an integrated starter generator system for a hybrid electric vehicle. Energies 2013, 6, 6102-6119.

33. Gazdac, A.M.; Betin, F.; Martis, C.S.; Biro, K. Investigation on the thermal behavior of the dual-rotor permanent magnet induction machine. In Proceedings of the 38th Conference on Industrial Electronics Society, Montreal, QC, Canada, 25-28 October 2012; pp. 1858-1863.

34. Huang, S.; Aydin, M.; Lipo, T.A. Electromagnetic vibration and noise assessment for surface mounted PM machines. In Proceedings of the Power Engineering Society Summer Meeting, Vancouver, BC, Canada, 15-19 July 2001; pp. 1417-1426.

35. Liu, Z.J.; Li, J.T. Accurate prediction of magnetic field and magnetic forces in permanent magnet motors using an analytical solution. IEEE Trans. Energy Convers. 2008, 23, 717-726.

36. Jiang, X.T.; Li, Y.; Fu, X.H.; Jiu, C.X.; Lu, Y.P. Analysis of radial electromagnetic force under different poles/slots matched in large torque PMSMs. In Proceedings of the 14th Conference on Electromagnetic Field Computation, Chicago, IL, USA, 9-12 May 2010. 
37. Sun, T.; Kim, J.M.; Lee, G.H.; Hong, J.P.; Choi, M.R. Effect of pole and slot combination on noise and vibration in permanent magnet synchronous motor. IEEE Trans. Magn. 2011, 47, 1038-1041.

38. Yang, H.; Chen, Y. Influence of radial force harmonics with low mode number on electromagnetic vibration of PMSM. IEEE Trans. Energy Convers. 2014, 29, 38-45.

39. Jung, J.-W.; Kim, D.-J.; Lee, S.-H.; Hong, J.-P.; Lee, D.-H. Effect of step skewed rotor type IPMSM on noise and vibration. In Proceedings of the 14th Conference on Electromagnetic Field Computation, Chicago, IL, USA, 9-12 May 2010.

40. Kim, K.C.; Lee, H.W.; Chun, Y.D.; Lee, J. Analysis of electromagnetic force distribution on end winding for motor reliance. IEEE Trans. Magn. 2010, 41, 4072-4074.

41. Mori, C.R.; Ishikawa, T. Force and vibration analysis of induction motor. IEEE Trans. Magn. 2005, 41, 1948-1951.

42. Morrison, C.R.; Siebert, M.W.; Ho, E.J. Electromagnetic forces in a hybrid magnetic-bearing switched-reluctance motor. IEEE Trans. Magn. 2008, 44, 4626-4638.

(C) 2015 by the authors; licensee MDPI, Basel, Switzerland. This article is an open access article distributed under the terms and conditions of the Creative Commons Attribution license (http://creativecommons.org/licenses/by/4.0/). 